\title{
OPEN Synergy of diffraction and spectroscopic techniques to unveil the crystal structure of antimonic acid
}

\author{
S. F. Mayer ${ }^{1 \bowtie}$, J. E. Rodrigues ${ }^{1,2}{ }^{2}$ I. Sobrados ${ }^{1}$, J. Gainza ${ }^{1}$, M. T. Fernández-Díaz ${ }^{3}$, C. Marini ${ }^{4}$, \\ M. C. Asensio ${ }^{1} \&$ J. A. Alonso ${ }^{1}$
}

The elusive crystal structure of the so-called 'antimonic acid' has been investigated by means of robust and state-of-the-art techniques. The synergic results of solid-state magic-angle spinning nuclear magnetic resonance spectroscopy and a combined Rietveld refinement from synchrotron $X$-ray and neutron powder diffraction data reveal that this compound contains two types of protons, in a pyrochlore-type structure of stoichiometric formula $\left(\mathrm{H}_{3} \mathrm{O}\right)_{1.20(7)} \mathrm{H}_{0.77(9)} \mathrm{Sb}_{2} \mathrm{O}_{6}$. Some protons belong to heavily delocalized $\mathrm{H}_{3} \mathrm{O}^{+}$subunits, while some $\mathrm{H}^{+}$are directly bonded to the oxygen atoms of the covalent framework of the pyrochlore structure, with O-H distances close to $1 \AA \AA$. A proton diffusion mechanism is proposed relying on percolation pathways determined by bond-valence energy landscape analysis. X-ray absorption spectroscopy results corroborate the structural data around $\mathrm{Sb}^{5+}$ ions at short-range order. Thermogravimetric analysis and differential scanning calorimetry endorsed the conclusions on the water content within antimonic acid. Additional 0.7 water molecules per formula were assessed as moisture water by thermal analysis.

One of the long-standing chemical identity issues is that corresponding to the so-called 'antimonic acid' (hereafter: AA), also referred to as hydrated antimony pentoxide (frequently termed HAP), antimony oxide hydrates, and $\mathrm{Sb}(\mathrm{V})$ hydroxide. This material has proven useful for a variety of applications due to its distinctive protonconducting nature $^{1-4}$, ionic exchangeability ${ }^{5-10}$, and radiation resistance ${ }^{7}$, serving as potential candidate for photocatalyst $^{11,12}$, fuel cells electrolyte ${ }^{13,14}$, heavy metals remover ${ }^{15,16}$, and for its application in electrochromic displays $^{3}$ or as precursor of several useful derivatives ${ }^{7,11,17-19}$, among others. This enigmatic substance was already described by J.J. Berzelius. In his pioneering work in 1812 , Berzelius published ${ }^{20}$ the preparation of a 'hydrated antimony pentoxide' by treating alkali antimonate with diluted nitric acid, while his junior student $\mathrm{H}$. Rose synthesized it in 1824 by hydrolysis of antimony pentachloride ${ }^{21}$. One of the earliest structural discussions concerning AA salts dates back from the mid-nineteenth century, where oxygen/metal ratios were elucidated, and six-sided crystals of magnesium, cobalt, and nickel antimonates are successfully synthesized ${ }^{22}$. More than a 100 years later, the atomic arrangement within the crystal of this elusive compound (or more properly speaking, series of compounds) is still being a topic of debate. Perhaps the first modern review gathering all these results is the one presented by J. W. Mellor ${ }^{17}$ in 1929. The most accepted formula for AA is $\mathrm{Sb}_{2} \mathrm{O}_{5} \cdot x \mathrm{H}_{2} \mathrm{O}$; depending on the synthesis and water content; water amounts varied from one to six $\mathrm{H}_{2} \mathrm{O}$ molecules per formula unit. A few years later, L. Pauling suggested the formula $\mathrm{HSb}(\mathrm{OH})_{6}$, equivalent to that of $\mathrm{Sb}_{2} \mathrm{O}_{5} \cdot 7 \mathrm{H}_{2} \mathrm{O}$, as the most likely composition for the acid phase ${ }^{23}$. This was supported by the water amount in the crystals and the ionic radius and behaviour of the $\mathrm{Sb}^{5+}$ cation, and it was widely accepted as a base of further compositional and structural determinations ${ }^{7,24-27}$. So forth, although researchers took many efforts to define the composition of AA, the crystal structure was totally unknown, perhaps given the difficulty of obtaining well-crystallized samples.

In a big attempt to shed light on the plausible structures adopted by AA-type compounds, Abe and Ito ${ }^{28}$ synthesized AA samples from antimony pentachloride under different acidic conditions, temperatures, and aging times, obtaining solids tagged as amorphous, glassy, and crystalline solids ${ }^{1}$. They demonstrated that the crystalline phase can be fostered at higher acid concentrations, longer aging times, and suitable aging temperatures,

\footnotetext{
${ }^{1}$ Instituto de Ciencia de Materiales de Madrid (ICMM), Consejo Superior de Investigaciones Científicas (CSIC), Sor Juana Inés de la Cruz 3, 28049 Madrid, Spain. European Synchrotron Radiation Facility, ESRF, 71 Avenue des Martyrs, 38043 Grenoble, France. ${ }^{3}$ Institut Laue Langevin (ILL), BP 156X, 38042 Grenoble, France. ${ }^{4}$ CELLS-ALBA Synchrotron, Cerdanyola del Valles, 08290 Barcelona, Spain. ${ }^{\circledR}$ email: s.mayer@csic.es
} 
regardless of the starting phase employed. The crystalline solid, of formula unit $\mathrm{Sb}_{2} \mathrm{O}_{5} \cdot 4 \mathrm{H}_{2} \mathrm{O}$, was defined in the $F d \overline{3} m$ space group, with a lattice constant of $10.38 \AA$. This was the first time that a pyrochlore-type phase was effectively defined for the AA crystalline oxides. With 6 days of difference, Baetsle and Huys announced similar results for AA samples obtained from $\mathrm{K}$ and $\mathrm{Na}$ antimonates, with similar unit-cell parameters and same compositions ${ }^{5}$, also concomitant with pioneering properties predicted for hydrated $\mathrm{Sb}_{2} \mathrm{O}_{5}{ }^{29}$.

In the present work, we have chosen a straightforward synthesis procedure, to our best knowledge described for the first time by Ozawa et al. ${ }^{3}$, yielding well-crystallized powder samples from easy-to-handle reactants, namely $\mathrm{Sb}_{2} \mathrm{O}_{3}$ and $\mathrm{H}_{2} \mathrm{O}_{2}$. It has been characterized by state-of-the-art techniques including neutron and synchrotron X-ray diffraction (NPD and SXRD, respectively), solid-state magic-angle spinning nuclear magnetic resonance spectroscopy (MAS NMR) and local order techniques like X-ray absorption spectroscopy (XAS), in complement with thermogravimetric analysis and differential scanning calorimetry (TGA/DSC), as well as scanning electron microscope (SEM). Our findings agree on a consistent picture of the atom-scale arrangement of AA, in a pyrochlore-type framework containing both $\mathrm{H}_{3} \mathrm{O}^{+}$and $\mathrm{H}^{+}$units accounting for the acidic behaviour of this material.

\section{Results and discussion}

Long-range order structural determinations. Crystalline AA powder was obtained in the form of a colloidal slurry by soft-chemistry procedures as described in "Methods". The obtained compound of nominal formula $\left(\mathrm{H}_{3} \mathrm{O}\right)_{p} \mathrm{H}_{2-p} \mathrm{Sb}_{2} \mathrm{O}_{6}$ and defect pyrochlore-type crystal structure has been investigated using long- and short-range characterization techniques, in order to determine its composition and atomic arrangement. Firstly, a peak indexing over a laboratory XRD pattern was performed as shown in Fig. 1a, confirming that AA adopts a cubic pyrochlore-type structure belonging to the $F d \overline{3} m\left(\# 227, O_{h}^{7}\right)$ space group, in agreement with previous reports $^{3,28}$. Briefly, pyrochlore-type oxides present a general formula $A_{2} B_{2} \mathrm{O}_{6} \mathrm{O}^{\prime}$, where $A$ is a voluminous mono-, di- or trivalent cation, $B$ is a smaller metal of higher oxidation state, and $\mathrm{O}^{\prime}$ is an oxygen atom that can be partially or even entirely absent, giving rise to the so-called defect pyrochlores $A_{2} B_{2} \mathrm{O}_{6} \mathrm{O}_{1-\delta}^{\prime}$. When $\mathrm{O}^{\prime}$ is present, two structural groups can be identified within the unit cell: a main covalent framework of $B_{2} \mathrm{O}_{6}$ corner-sharing octahedra, and a sub-lattice $A_{2} \mathrm{O}^{\prime}$, interspersed in a tetrahedral arrangement. Once the XRD data of AA were indexed in the $F d \overline{3} m$ space group, the crystalline structure was fully determined by a combined Rietveld refinement from SXRD and NPD data collected at room temperature. Patterns from NPD and SXRD data contained sharp diffraction peaks, consistent with a cubic pyrochlore phase with $a=10.36052(15) \AA$, as displayed in Fig. 1b,c. An origin choice \# 2 at $\overline{3} m$ was adopted for this analysis. The in-detail refinement procedure is described in the Supplementary Information, while the refinement parameters can be found in "Methods".

The final refinement includes $\mathrm{Sb}$ and $\mathrm{O} 1$ atoms located at $16 d(1 / 2,1 / 2,1 / 2)$ and $48 f(x, 1 / 8,1 / 8)$ Wyckoff sites, constituting the covalent $\mathrm{Sb}_{2} \mathrm{O}_{6}{ }^{2-}$ framework of the pyrochlore oxide. Two types of $\mathrm{H}$ atoms were identified: $\mathrm{H} 1$ located at $96 \mathrm{~g}(x, x, z)$ sites, constituting together with the $\mathrm{O} 2$ atoms at $32 e(x, x, x)$ the hydronium $\mathrm{H}_{3} \mathrm{O}^{+}$units, and $\mathrm{H} 2$ species located at $48 f(x, 1 / 8,1 / 8)$ positions, directly linked to the $\mathrm{Sb}_{2} \mathrm{O}_{6}$ covalent framework. O2 can be considered to be the $\mathrm{O}^{\prime}$ atoms of the standard pyrochlore structure. Ultimately, the individual atomic anisotropic displacement factors for each non-equivalent atom were determined, with the only exception of the $\mathrm{H} 2$ species, which was modelled as an isotropic sphere. This is due to a strong divergence of the model when attempted to be anisotropically determined, probably due to its vicinity to the resonant $\mathrm{H} 1$ atom. Attempts to incorporate additional water or hydronium molecules within the structure, as for example centred at $8 b$ sites occupying the empty cages generated by the main framework or along the main diagonal (as reported by Slade et al. ${ }^{30}$ ), resulted in atomic site occupation factors (SOFs) close to zero, many times even reaching negative isotropic displacement factors. This way, tens of feasible structural alternatives and atomic incorporations were discarded, many of which containing constrains or restrains varying $\mathrm{O}-\mathrm{H}$ bond length distances and $\mathrm{O} 2 / \mathrm{H} 1,2 \mathrm{SOF}$ ratios. No preferred orientation is expected to occur due to the isotropy of the cubic structure and the octahedral shape of AA microcrystals, and neither the parameters of preferred orientation nor roughness were refined as they showed no improvement in the reliability factors.

Occupancies of $\mathrm{H} 1, \mathrm{H} 2$, and $\mathrm{O} 2$ atoms were constrained to each other according to the MAS NMR analysis, and strongly endorsed by a TGA/DSC study, as explained in the water and proton content assessment section; occupancy constrains partially relied on the electroneutrality of the crystal structure. For the Sb and O1 elements, small displacement ellipsoids were obtained $\left(U_{\text {eq }}=0.98(2) \times 10^{-2}\right.$ and $0.83(10) \times 10^{-2} \AA^{2}$, respectively), denoting small vibrational and delocalization of the scattering contributions. In contrast, although far smaller than those obtained in the 'Case B' scenario described in the Supplementary Information, O2 and H1 atoms belonging to the hydronium units exhibited rather large cigar-shaped (prolate type) displacement ellipsoids of $U_{\text {eq }}=5.4(4) \times 10^{-2}$ and $6.7(8) \times 10^{-2} \AA^{2}$, stretched along the $(x, x, x)$ direction. They are reminiscent to those described in the $\left(\mathrm{H}_{3} \mathrm{O}\right)_{1+p} \mathrm{Sb}_{1+p} \mathrm{Te}_{1-p} \mathrm{O}_{6}$ series $^{31}$. This is expected, considering their high multiplicity and their relatively small occupancy, as well as by the fact that the hydronium units may rattle within the wide cavities generated by the $\mathrm{Sb}_{2} \mathrm{O}_{6}{ }^{2-}$ framework, where a high diffusivity of the hydronium units across its channels is expected. Finally, $\mathrm{H} 2$ atoms presented somewhat in-between isotropic displacements $\left(U_{\text {iso }}=3.626(1) \times 10^{-2} \AA^{2}\right)$, suggesting lower ionic mobility and lower atomic delocalization. The final structure achieved by Rietveld refinement of both SXRD and NPD diffraction data for the AA is exhibited in detail in Fig. 1d-f. Besides, an animated representation of the $\mathrm{H}_{3} \mathrm{O}^{+}$units and $\mathrm{H} 2$ protons in their $\mathrm{Sb}_{2} \mathrm{O}_{6}{ }^{2-}$ framework cavity is displayed in Supplementary File 2, and its caption in Supplementary File 1. A powder diffraction CIF file is also available as Supplementary Information.

At room temperature, convergence $R_{B}$ Bragg R-factors achieved values of $3.55 \%$ for SXRD and $2.47 \%$ for NPD, suggesting that the calculated model fits reasonably well with the experimental data. To summarize, all these agreement factors, together with the final atomic positions, anisotropic and isotropic equivalent displacement factors, and the SOF of each species are recapitulated in Table 1. 


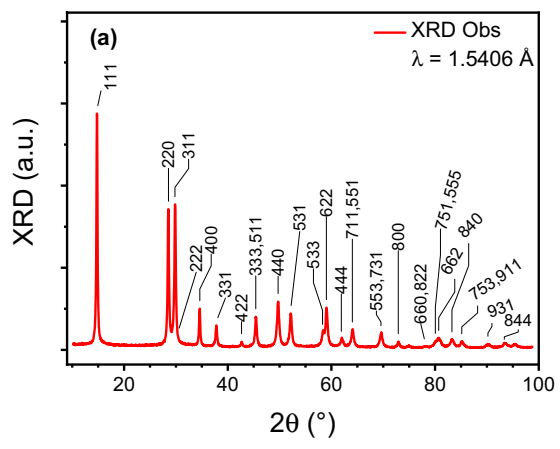

(d)

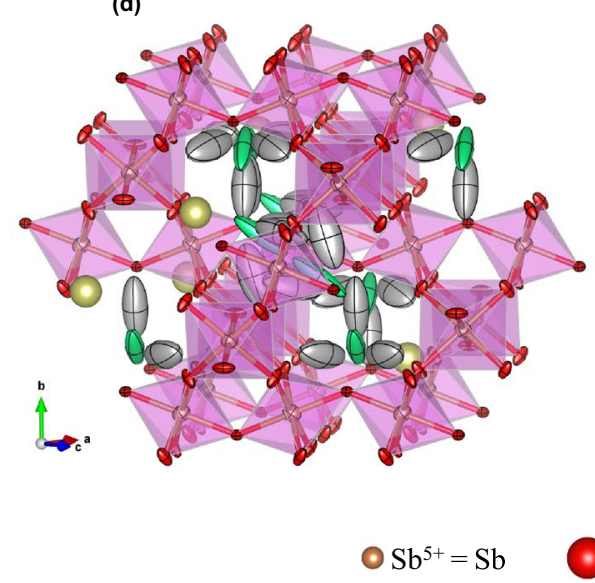

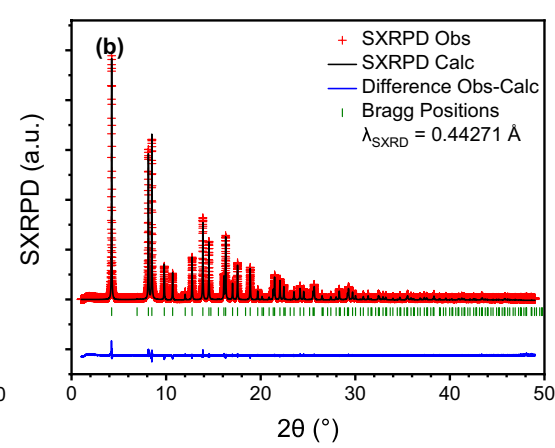

(e)

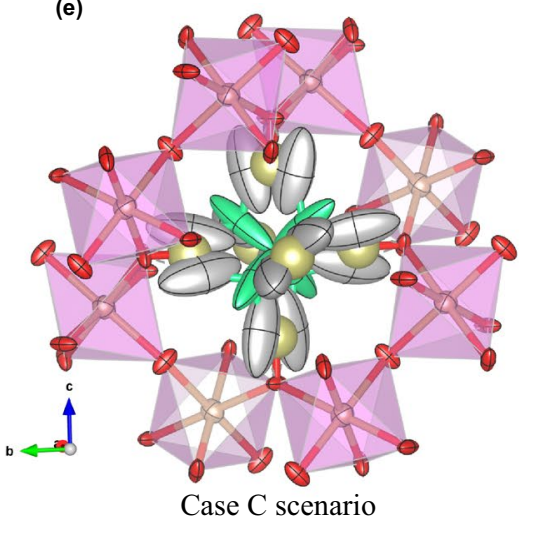

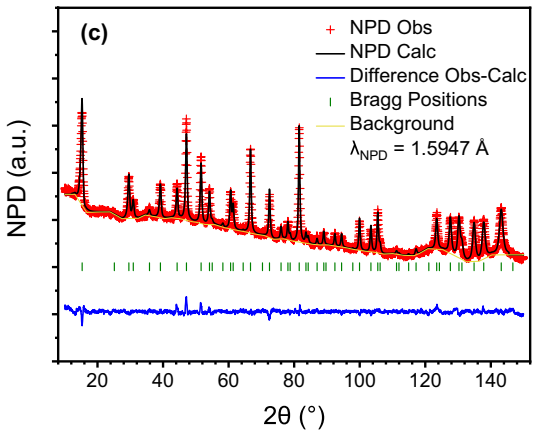

(f)

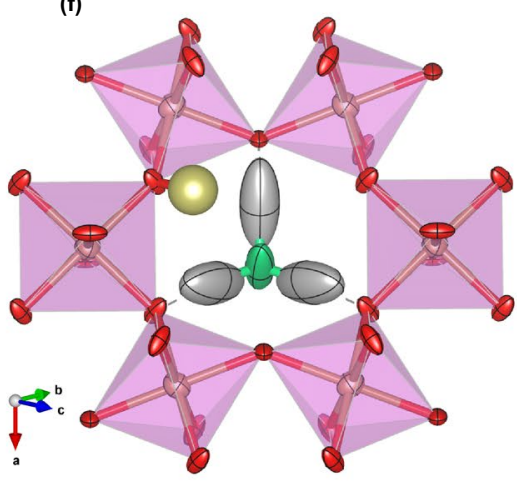

$\mathrm{H}^{1+}=\mathrm{H} 2$

Figure 1. Diffraction patterns and structural representation of AA. (a) Laboratory XRD diagram of $\left(\mathrm{H}_{3} \mathrm{O}\right)_{1.20(7)} \mathrm{H}_{0.77(9)} \mathrm{Sb}_{2} \mathrm{O}_{6}(\lambda=1.5406 \AA \mathrm{Cu} \mathrm{Ka}$ radiation) with peaks indexed in a face-centred cubic unit cell with $a=10.36052(15) \AA$. (b,c) Plots from the combined Rietveld refinement from SXRD and NPD data. Experimental (red crosses), calculated (solid black line), and difference (solid blue line at the bottom) (b) SXRD $\left(\lambda_{\text {SXRD }}=0.44271 \AA\right)$ and $(\mathbf{c})$ NPD $\left(\lambda_{\mathrm{NPD}}=1.5947 \AA\right)$ patterns, with Bragg reflection positions marked by vertical green bars. (d-f) Views of the AA pyrochlore final structure ('Case C' scenario described in the Supporting Information). Atoms of the three panels are presented as anisotropic displacement ellipsoids at a 95\% probability level. Caption colour reference at the bottom of Figure is common to all figures. (d) Representation of a snapshot of the crystal approximately along the [101] direction: the covalent framework made by the $\left(\mathrm{Sb}^{5+} \mathrm{O}_{6}\right)$ corner-sharing octahedra consists of $16 d$ (Sb, brown) and $48 f(\mathrm{O} 1$, red) fully occupied sites, with golden $(\mathrm{H} 2)$ protons linked to the skeleton $\mathrm{O} 1$ atoms at distances of 1.13(6) $\AA$. Hydronium subunits are constituted by silver (H1) protons bonded to green (O2) oxygens at 1.323(11) $\AA$ in a tetrahedral distribution (with $104.0(16)^{\circ}$ angles). These atoms present high mobility, with prolate anisotropic ellipsoids oriented along the $(x, x, x)$ main threefold diagonal. (e) Close up of the statistical distribution of a single cavity wherein the $\mathrm{O} 2$ and $\mathrm{H} 1$ are distributed at $32 e$ and $96 \mathrm{~g}$ Wyckoff positions, respectively, with SOFs close to $0.301(2)$, and $\mathrm{H} 2$ atoms at $48 f$ sites exhibiting a SOF of $0.129(15)$. Only $1.20(7) \mathrm{H}_{3} \mathrm{O}^{+}$groups and $0.77(9) \mathrm{H} 2$ species are statistically present in each cavity. (f) Snapshot of a single octahedra-sharing crown with a hydronium subunit and a $\mathrm{H} 2$ proton. In dotted lines: $\mathrm{H} 1$ atoms of the $\mathrm{H}_{3} \mathrm{O}^{+}$subunit establish $\mathrm{H}$ bonds with the $\mathrm{O} 1$ atoms at about 1.400(10) $\AA$.

The crystallographic formula obtained from the structural refinement is $\left(\mathrm{H}_{3} \mathrm{O}\right)_{1.20(7)} \mathrm{H}_{0.77(9)} \mathrm{Sb}_{2} \mathrm{O}_{6}$, which presents electroneutrality within the standard deviation and is also endorsed by the low Rietveld reliability factors and the reasonable equivalent isotropic displacement factors obtained for each mobile atom. It is interesting to examine the ionic conduction path obtained from a bond-valence energy landscape (BVEL) study of the crystal, illustrated in Fig. 2a-c. The conduction pathway, highlighted with a blue isosurface, involves both types of $\mathrm{H}$ atoms and exhibits an isotropic distribution along the three axes. The percolation of the $\mathrm{H}$ atoms presents a very low activation energy of $0.13 \mathrm{eV}$ and a noticeably large volume fraction of the unit cell for ion mobility of $72.38 \%$ for the given parameters, providing the mechanism for the high ionic intracrystalline proton conduction announced by several authors ${ }^{3,4,13,32}$. The average site-energy computed by bond-valence theory for both mobile protons is $-2.95 \mathrm{eV}$, differing between both species in only $0.12 \mathrm{eV}$.

The $\mathrm{H} 2$ atom is bonded to the framework in a $\mathrm{Sb}^{5+}-\mathrm{OH}$ fashion, with hydroxyl interatomic distances $\mathrm{H} 2-$ $\mathrm{O} 1$ of $1.13(6) \AA$. The $\mathrm{O} 2$ at $32 e$ Wyckoff sites is coordinated by three $\mathrm{H} 1$ species at $96 \mathrm{~g}$ positions in a tetrahedral arrangement, with internal $\mathrm{H} 1-\mathrm{O} 2-\mathrm{H} 1$ angles of $104.0(16)^{\circ}$. The lone electron pair of the oxygen atoms belonging to the hydronium groups are oriented in the $8 a(1 / 8,1 / 8,1 / 8)$ direction. The $\mathrm{H} 1$ atoms are located about 1.400 (10) $\AA$ away from the O1 oxygen of the covalent framework, with which a hydrogen bond is likely established. Remarkably, the mean $\mathrm{H} 1-\mathrm{O} 2$ interatomic distance within the hydronium unit is 1.323(11) $\AA$, which might seem rather large for a well-established (coordinated) covalent bond. The reason for this is that, statistically, 


\begin{tabular}{|c|c|c|}
\hline Pyrochlore & Antimonic acid & \\
\hline$a(\AA)$ & 10.36073(9) & \\
\hline$V\left(\AA^{3}\right)$ & $1112.17(2)$ & \\
\hline$S b, 16 d(1 / 2,1 / 2,1 / 2)$ & $\mathrm{Sb}^{5+}$ & \\
\hline$u_{11}=u_{22}=u_{33}{ }^{a}$ & $0.01034(15)$ & \\
\hline$u_{12}=u_{13}=u_{23}{ }^{a}$ & $0.0008(2)$ & \\
\hline$U_{\mathrm{eq}}\left(\AA^{2}\right)$ & 0.01034(15) & \\
\hline SOF & 1.0000 & \\
\hline $01,48 f(x, 1 / 8,1 / 8)$ & $\mathrm{O}^{2-}$ & \\
\hline$x$ & 0.43095(17) & \\
\hline$u_{11}{ }^{\mathrm{a}}$ & $0.0038(13)$ & \\
\hline$u_{22}=u_{33}{ }^{\mathrm{a}}$ & $0.0113(9)$ & \\
\hline$u_{23}^{\mathrm{a}, \mathrm{b}}$ & $-0.0059(9)$ & \\
\hline$U_{\text {eq }}\left(\AA^{2}\right)$ & $0.0088(10)$ & \\
\hline SOF & 1.0000 & \\
\hline $02,32 e(x, x, x)$ & $\mathrm{O}^{2-}$ & \\
\hline$x$ & $0.0652(7)$ & \\
\hline$u_{11}=u_{22}=u_{33}{ }^{\mathrm{a}}$ & $0.055(4)$ & \\
\hline$u_{12}=u_{13}=u_{23}{ }^{\mathrm{a}}$ & $0.043(4)$ & \\
\hline$U_{\mathrm{eq}}\left(\AA^{2}\right)$ & $0.055(4)$ & \\
\hline SOF & $0.301(17)$ & \\
\hline H1, $96 g(x, x, z)$ & $\mathbf{H}^{+}$ & \\
\hline$x$ & $0.3321(8)$ & \\
\hline$z$ & $0.0602(17)$ & \\
\hline$u_{11}=u_{22}{ }^{\mathrm{a}}$ & $0.033(4)$ & \\
\hline$u_{33}{ }^{\mathrm{a}}$ & $0.139(16)$ & \\
\hline$u_{12}{ }^{\mathrm{a}}$ & $0.011(6)$ & \\
\hline$u_{13}=u_{23}{ }^{\mathrm{a}}$ & $-0.022(8)$ & \\
\hline$U_{\mathrm{eq}}\left(\AA^{2}\right)$ & $0.068(8)$ & \\
\hline SOF & $0.301(2)$ & \\
\hline $\mathrm{H} 2,48 f(x, 1 / 8,1 / 8)$ & $\mathbf{H}^{+}$ & \\
\hline$x$ & $0.323(4)$ & \\
\hline$U_{\mathrm{eq}}\left(\AA^{2}\right)$ & $0.036261(10)$ & \\
\hline SOF & $0.129(15)$ & \\
\hline Reliability factors & SXRD & NPD \\
\hline $\mathrm{R}_{\mathrm{p}}(\%)$ & 6.85 & 0.893 \\
\hline $\mathrm{R}_{\mathrm{wp}}(\%)$ & 10.5 & 1.22 \\
\hline $\mathrm{R}_{\exp }(\%)$ & 5.53 & 1.86 \\
\hline$\chi^{2}$ & 3.60 & 0.433 \\
\hline $\mathrm{R}_{\text {Bragg }}(\%)$ & 3.55 & 2.47 \\
\hline
\end{tabular}

Table 1. Structural parameters for AA refined from combined SXRD and NPD data. Unit-cell (a), fractional atomic coordinates $(x, z)$, Debye-Waller anisotropic $\left(u_{i j}\right)$ and equivalent isotropic $\left(U_{\text {eq }}\right)$ displacement factors, SOFs and Rietveld agreement factors $\left(\mathrm{R}_{\mathrm{p}}, \mathrm{R}_{\mathrm{wp}}, \mathrm{R}_{\text {exp }}, \chi^{2}\right.$, and $\left.\mathrm{R}_{\text {Bragg }}\right)$ for $\left(\mathrm{H}_{3} \mathrm{O}\right)_{1.20(7)} \mathrm{H}_{0.77(9)} \mathrm{Sb}_{2} \mathrm{O}_{6}$, with cubic space group $F d \overline{3} m$ (\# 227) and $Z=8$, from dual SXRD and NPD data refinement collected at $298 \mathrm{~K}$ $\left(\lambda_{\text {SXRD }}=0.44271 \AA, \lambda_{\text {NPD }}=1.5947 \AA\right.$, Origin Choice \# 2). ${ }^{a}$ Anisotropic $u_{\mathrm{ij}}\left(\times 10^{4}\right) .{ }^{\mathrm{b}} \boldsymbol{u}_{12}=\boldsymbol{u}_{13}=0$.

there are 1.20(7) hydronium groups within the framework per formula unit, but in reality, only one or two subunits may fit in each cavity, off-centre of the $8 a(1 / 8,1 / 8,1 / 8)$ Wyckoff site and displaced along the $(x, x, x)$ direction. Therefore, about eight cavities hold one single hydronium ion, whereas two $\mathrm{H}_{3} \mathrm{O}^{+}$subunits must be contained in two of them. In the latter case, owing to the repulsive electrostatic forces between the two highly electronegative $\mathrm{O} 2$ atoms fitting close to each other at a mean 1.752(10) $\AA$ distance, the $\mathrm{H}_{3} \mathrm{O}^{+}$units accommodate even farther from the $8 a$ site. Due to this shift along the main diagonal, $\mathrm{H} 1$ atoms become closer to the $\mathrm{O} 1$ atoms of the covalent framework, fostering a resonance in which the $\mathrm{H} 1$ protons may jump into the $\mathrm{H} 248 \mathrm{f}$ position and establish a hydrogen bond with their correspondent O2 at a mean distance of 1.679(17) $\AA$. Recently, we have found a similar shift along the main diagonal direction due to the increasing occupancy of $\mathrm{H}_{3} \mathrm{O}^{+}$groups on a related family of $\mathrm{Sb}$ and Te pyrochlore-like acid oxides ${ }^{31}$. Certainly, it was confirmed that the shift of the $\mathrm{O}^{\prime}$ atoms along this path, regarding the lower-multiplicity $8 a(1 / 8,1 / 8,1 / 8)$ Wyckoff site, is frequent within the pyrochlore family ${ }^{33}$. 
(a)

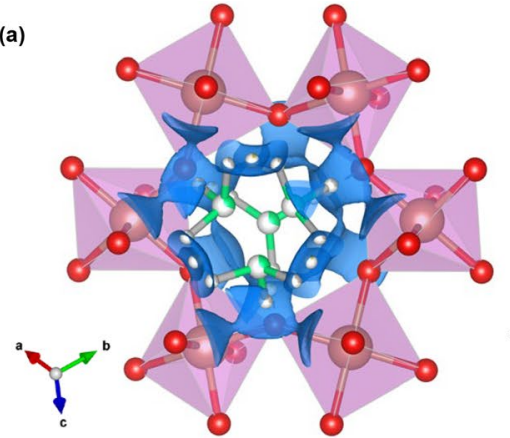

(b)

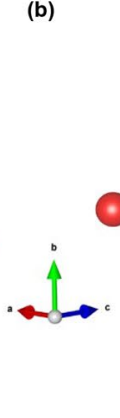

(d)

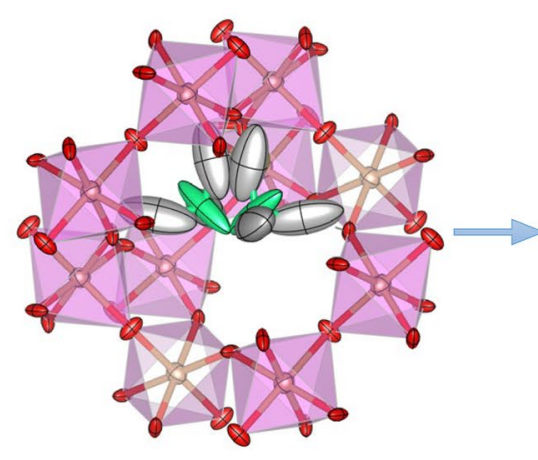

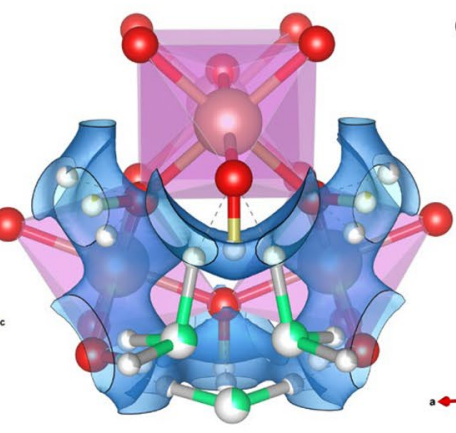
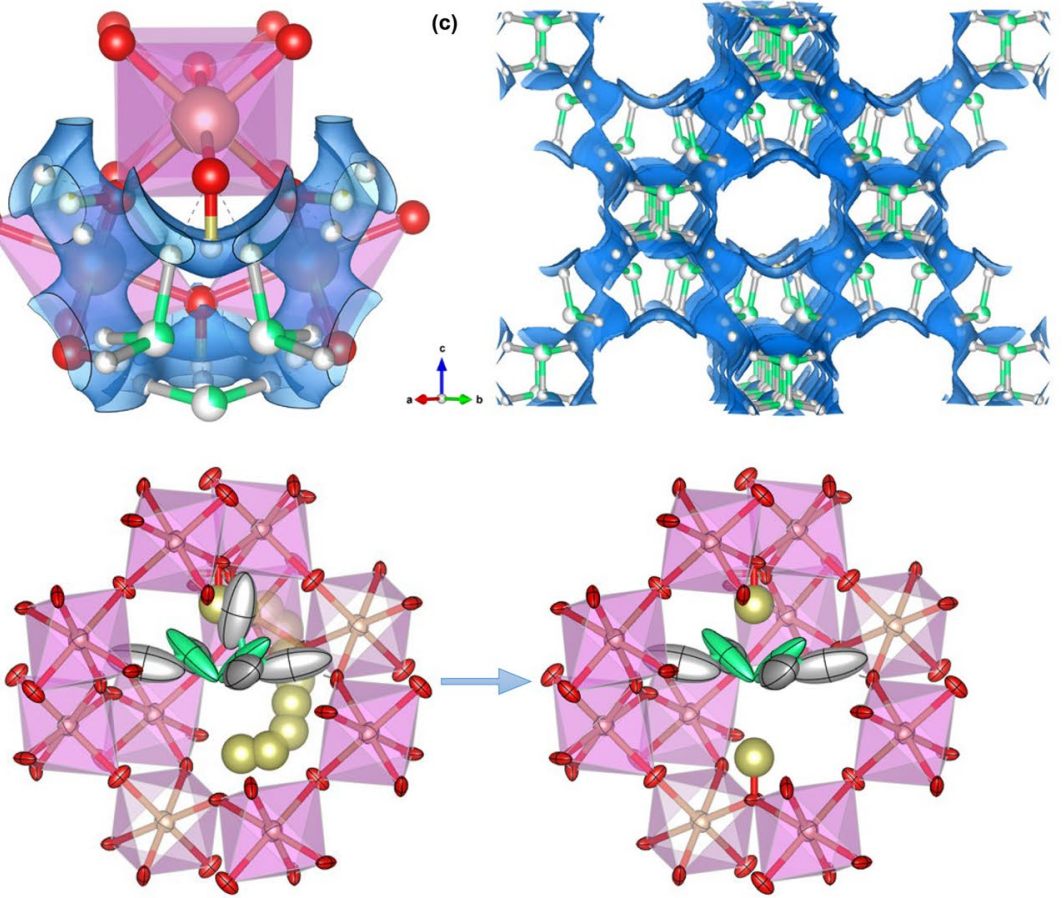

Case C scenario

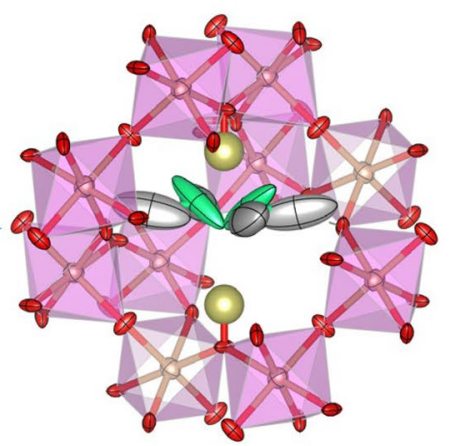

Figure 2. Proton percolation pathway and mechanism in the AA ('Case C' scenario described in the Supplementary Information). Atoms in all six panels are presented as anisotropic displacement ellipsoids at a $95 \%$ probability level. The colour reference is the same one used in Fig. 1. (a,b) Close up of the AA final structure; the ionic percolation path is highlighted in blue. The pathway involves both $\mathrm{H}^{+}$species in a $3 \mathrm{D}$ interconnected arrangement, generating the $3 \mathrm{D}$ percolation isosurface defined for the AA. The ionic percolation begins with a low percolation activation energy barrier of $0.13 \mathrm{eV}$. (c) Proton percolation pathway in a simplified view of the AA unit cell approximately along the [110] direction. For the sake of clarity, the $\mathrm{Sb}_{2} \mathrm{O}_{6}{ }^{2-}$ octahedra-sharing covalent framework is hidden, and only the $\mathrm{H}_{3} \mathrm{O}^{+}$acid groups and the $\mathrm{H} 2$ species are visible. Statistically, less than a third of the hydronium units here figured are present. (d) Proposed ionic migration mechanism of two $\mathrm{H} 1$ atoms from $96 g$ to $48 f(\mathrm{H} 2)$ Wyckoff sites, for those cages wherein two $\mathrm{H}_{3} \mathrm{O}^{+}$subunits coexist. The repulsive electrostatic forces between the two $\mathrm{O} 2$ species would force their shift away from the $8 a(1 / 8,1 / 8,1 / 8)$ along the $(x, x, x)$ direction. One of the in-between protons is shared between the two $\mathrm{O} 2$ atoms and the $\mathrm{O} 1$ framework oxygen, while the other is relocated at the antipodal position of the cavity by following the percolation path highlighted in panels $(\mathbf{a}-\mathbf{c})$, achieving an electrostatic stability.

Therefore, when two hydronium groups get close to each other, the central protons become prone to delocalization. Here, it is very likely that one of these in-between protons starts resonating and becomes a shared ion between the two $\mathrm{O} 2$ and the $\mathrm{O} 1$ oxygens. Such a scheme would entail the bonding of four protons to two $\mathrm{O} 2$, the share of a fifth $\mathrm{H}^{+}$between these and one $\mathrm{O} 1$ oxygen, and the sixth remaining $\mathrm{H}^{+}$species leaving the $\mathrm{H}_{3} \mathrm{O}^{+}$groups behind by following the ionic conduction path and bonding to the opposite $\mathrm{O} 1$ at a mean $\mathrm{O} 2-\mathrm{H} 2$ distance of 2.811(12) $\AA$. As there are statistically less than $0.8 \mathrm{H} 2$ atoms per cavity, there is room for the proposed mechanism as some of the cages will not present an $\mathrm{OH}$ hydroxyl group at all. A schematic representation of this effect is shown in Fig. 2d.

The determined $\mathrm{Sb}-\mathrm{O} 1-\mathrm{Sb}$ angle and $\mathrm{Sb}-\mathrm{O} 1$ distances within the $\mathrm{Sb}_{2} \mathrm{O}_{6}{ }^{2-}$ covalent network are $137.33(3)^{\circ}$ and 1.9663(12) $\AA$, respectively, which are larger than those of $136.39(2)^{\circ}$ and $1.9624(5) \AA$ recently reported for an AA derivative, viz. $\mathrm{Sb}_{6} \mathrm{O}_{13}$, obtained by thermal decomposition of the former ${ }^{19}$. The unit-cell parameter is also longer for $\mathrm{AA}$, about $0.53 \%$ more than that of $\mathrm{Sb}_{6} \mathrm{O}_{13}(10.36052(15)$ vs $10.30653(11) \AA)$. A wider and bigger cavity for the hydrated sample is consistent with the presence of $1.20(7)$ voluminous $\mathrm{H}_{3} \mathrm{O}^{+}$groups per cage, in contrast with the $0.5 \mathrm{Sb}^{3+}{ }_{2}-\mathrm{O}^{\prime}$ groups found in the calcined sample. The main interatomic distances and angles obtained are summarized in Table 2.

The obtained Rietveld profiles are exhibited in Fig. 1b,c and in more detail in Supplementary Fig. S1. The domain size assessment, determined by Scherrer's ${ }^{34,35}$ equation from SXRD data, yields a crystallite of $42.00(8) \mathrm{nm}$ average apparent size. Instrumental broadening was deconvoluted for Scherrer's apparent domain size determination, see "Methods" for more details.

Water and proton content assessment. The occupancies of $\mathrm{O} 2, \mathrm{H} 1$, and $\mathrm{H} 2$ species used on the combined Rietveld refinement were determined by means of MAS NMR applied to dry AA. This is a powerful technique to identify the different ${ }^{1} \mathrm{H}$ species that may be found within the crystal structure. Prior to this analysis, the sample was dried at $105-107^{\circ} \mathrm{C}$ to eliminate all contributions to the final spectrum that could come from adsorbed water. The resulting deconvolution, shown in Fig. 3a, is mainly made up of two components with dif- 


\begin{tabular}{|c|c|c|c|}
\hline Bond (occurrence) & Distance $(\AA)$ & Atoms set & Angle $\left(^{\circ}\right)$ \\
\hline \multicolumn{4}{|l|}{$\left(\mathrm{Sb}_{2} \mathrm{O}_{6}{ }^{2-}\right)$ covalent framework } \\
\hline $\mathrm{Sb}-\mathrm{O} 1(\times 6)$ & $1.9663(12)$ & $\mathrm{Sb}-\mathrm{O} 1-\mathrm{Sb}$ & 137.33(3) \\
\hline \multirow[t]{4}{*}{$\mathrm{O} 1-\mathrm{H} 2(\times 1)$} & $1.12(4)$ & $\mathrm{O} 1-\mathrm{Sb}-\mathrm{O} 1$ & $180.00(6)$ \\
\hline & & $\mathrm{O} 1-\mathrm{Sb}-\mathrm{O} 1$ & $87.39(4)$ \\
\hline & & $\mathrm{O} 1-\mathrm{Sb}-\mathrm{O} 1$ & $92.61(8)$ \\
\hline & & $\mathrm{Sb}-\mathrm{O} 1-\mathrm{H} 2$ & $111.3(14)$ \\
\hline \multicolumn{4}{|l|}{$\left(\mathrm{H}_{3} \mathrm{O}^{+}\right)$unit } \\
\hline $\mathrm{O} 2-\mathrm{H} 1(\times 3)$ & $1.323(11)$ & $\mathrm{H} 1-\mathrm{O} 2-\mathrm{H} 1$ & $104.0(16)$ \\
\hline Non-bonding pairs (occurrence) & Distance $(\AA)$ & Atoms set & Angle $\left(^{\circ}\right)$ \\
\hline \multicolumn{4}{|l|}{ Non-bonding atoms } \\
\hline $\mathrm{Sb}-\mathrm{Sb}(\times 6)$ & $3.66307(2)$ & $\mathrm{Sb}-\mathrm{O} 1-\mathrm{O} 2$ & 98.3(3) \\
\hline $\mathrm{Sb}-\mathrm{O} 1(\times 6)$ & $3.7791(6)$ & $\mathrm{Sb}-\mathrm{O} 1-\mathrm{O} 2$ & $110.1(3)$ \\
\hline $\mathrm{Sb}-\mathrm{O} 2(\times 12)$ & $3.845(7)$ & $\mathrm{Sb}-\mathrm{O} 1-\mathrm{H} 1$ & $109.0(7)$ \\
\hline $\mathrm{Sb}-\mathrm{H} 2(\times 6)$ & $2.59(3)$ & O1-O1-H2 & $135(3)$ \\
\hline $\mathrm{Sb}-\mathrm{H} 1(\times 12)$ & $2.760(10)$ & $\mathrm{O} 1-\mathrm{O} 2-\mathrm{H} 2$ & $108.7(6)$ \\
\hline $\mathrm{O} 1-\mathrm{H} 1(\times 2)$ & $1.400(10)$ & $\mathrm{O} 1-\mathrm{H} 2-\mathrm{O} 2$ & $149(3)$ \\
\hline $\mathrm{O} 1-\mathrm{H} 1(\times 4)$ & $2.471(9)$ & $\mathrm{O} 1-\mathrm{H} 2-\mathrm{O} 2$ & $92(2)$ \\
\hline $\mathrm{O} 1-\mathrm{H} 1(\times 4)$ & $3.111(9)$ & $\mathrm{O} 1-\mathrm{H} 2-\mathrm{H} 1$ & $129(2)$ \\
\hline $\mathrm{O} 1-\mathrm{O} 2(\times 2)$ & $2.697(7)$ & $\mathrm{O} 1-\mathrm{H} 2-\mathrm{H} 1$ & $88(2)$ \\
\hline $\mathrm{O} 1-\mathrm{O} 2(\times 2)$ & $3.034(7)$ & O1-H1-O2 & 164.1(9) \\
\hline $\mathrm{O} 2-\mathrm{O} 2(\times 3)$ & 1.752(10) & $\mathrm{H} 1-\mathrm{O} 1-\mathrm{H} 2$ & 66(2) \\
\hline $\mathrm{O} 2-\mathrm{O} 2(\times 1)$ & $2.340(10)$ & $\mathrm{H} 1-\mathrm{O} 2-\mathrm{H} 2$ & 93.5(9) \\
\hline $\mathrm{O} 2-\mathrm{H} 2(\times 2)$ & 1.679(17) & $\mathrm{H} 1-\mathrm{O} 2-\mathrm{H} 2$ & 115.3(15) \\
\hline $\mathrm{O} 2-\mathrm{H} 2(\times 2)$ & $2.788(7)$ & $\mathrm{H} 2-\mathrm{H} 1-\mathrm{O} 2$ & 99.3(9) \\
\hline $\mathrm{O} 2-\mathrm{H} 2(\times 2)$ & 2.811(12) & $\mathrm{H} 2-\mathrm{H} 2-\mathrm{H} 2$ & 65.0(15) \\
\hline $\mathrm{H} 2-\mathrm{H} 2(\times 4)$ & $2.90(4)$ & $\mathrm{H} 2-\mathrm{H} 2-\mathrm{H} 2$ & $57.5(3)$ \\
\hline $\mathrm{H} 2-\mathrm{H} 2(\times 1)$ & $4.10(6)$ & O1-O1-O1 & 107.56(6) \\
\hline $\mathrm{H} 2-\mathrm{H} 1(\times 4)$ & $2.250(10)$ & O1-O1-O1 & 111.181(16) \\
\hline $\mathrm{H} 2-\mathrm{H} 1(\times 2)$ & $3.33(2)$ & & \\
\hline $\mathrm{H} 2-\mathrm{H} 1(\times 4)$ & $3.18(3)$ & & \\
\hline $\mathrm{H} 2-\mathrm{H} 1(\times 2)$ & $4.02(4)$ & & \\
\hline H1-H1 (×2) & 2.085(19) & & \\
\hline $\mathrm{H} 1-\mathrm{H} 1(\times 2)$ & $2.92(2)$ & & \\
\hline
\end{tabular}

Table 2. Selected interatomic distance and angles refined from combined SXRD and NPD data. Main interatomic distances and angles for $\left(\mathrm{H}_{3} \mathrm{O}\right)_{1.20(7)} \mathrm{H}_{0.77(9)} \mathrm{Sb}_{2} \mathrm{O}_{6}$, with cubic space group $F d \overline{3} m$ (\#227) and $Z=8$, from dual SXRD and NPD data refinement collected at $298 \mathrm{~K}\left(\lambda_{\mathrm{SXRD}}=0.44271 \AA, \lambda_{\mathrm{NPD}}=1.5947 \AA\right.$, Origin Choice \# 2). $\mathrm{Sb}_{2} \mathrm{O}_{6}{ }^{2-}$ covalent framework, $\mathrm{H}_{3} \mathrm{O}^{+}$subunit, and non-bonding atoms categories are classified. In the latter, only meaningful distances and angles from atomic pairs and triplets of near non-bonding elements are summarized.

ferent widths and intensities, corresponding to the two proton types observed by Rietveld refinement from NPD data. Additionally, a small component has been introduced to the deconvolution at a chemical shift of $1 \mathrm{ppm}$, corresponding to a parasitic signal from the organic rotor cap. The chemical shift values of the main two contributions are rather similar to each other $(8.70$ for $\mathrm{H} 1$ and $8.46 \mathrm{ppm}$ for $\mathrm{H} 2)$ and, in both cases, higher than those of the water molecule (5 ppm), indicating a somewhat stronger acidity of the protons. The dependence of the chemical shift or anisotropy with the orientation regarding the external magnetic field $\mathrm{B}_{0}$ is not pronounced, and the calculated isotropic chemical shift (tabulated in Table 3) coincides with the position of the main components. At the same time, proton contributions ( $\mathrm{H} 1$ and $\mathrm{H} 2$ ) present similar small chemical shift anisotropy (usually termed CSA) patterns, which are slightly broadened by anisotropic interactions, meaning that the structural environment is slightly distorted in both cases. Signal contribution widths, on the other hand, are noticeably different; in NMR, a higher width may indicate less mobility due to greater interaction with the surface and a higher heterogeneity of structural positions. From the two main deconvoluted signals, the wider and less significant one $(6.5 \mathrm{ppm}$ wide, $17.49 \%)$ is assigned to the more restrained, short-bonded $\mathrm{H} 2$ protons, while the narrow and stronger signal (2.5 ppm, 81.30\%) corresponds to the $\mathrm{H} 1$ protons constituting the high-mobility hydronium groups. The relationship between the two areas is 4.648 , in close agreement with the $\mathrm{H} 1 / \mathrm{H} 2$ Rietveld SOFs ratio of 4.674. Principal elements deduced from sideband patterns are given in Table 3 , where isotropic chemical shift, anisotropy, and asymmetry parameters corresponding to each site are also included. A brief explanation of the tabulated elements is presented in "Methods". 
(a)

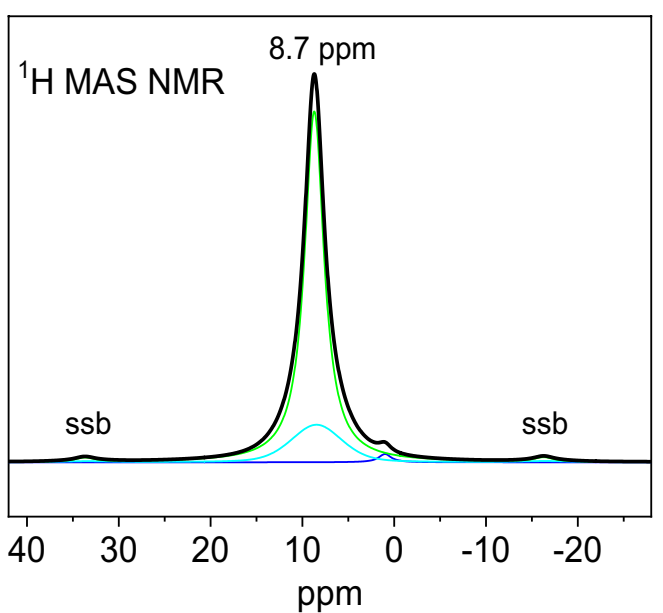

(c)

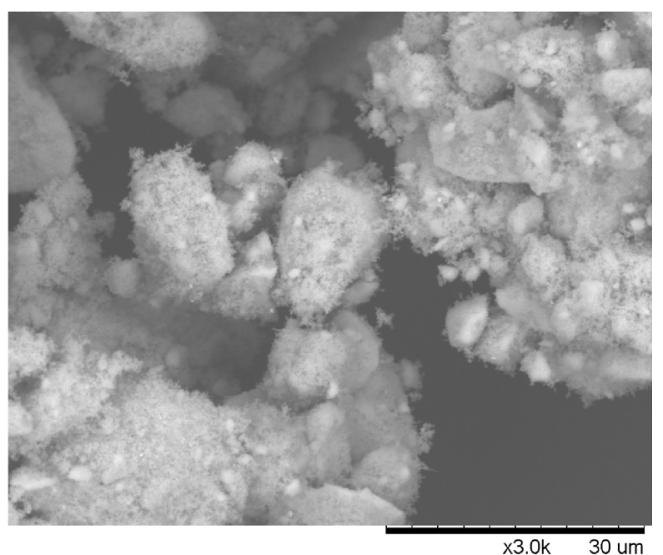

(b)

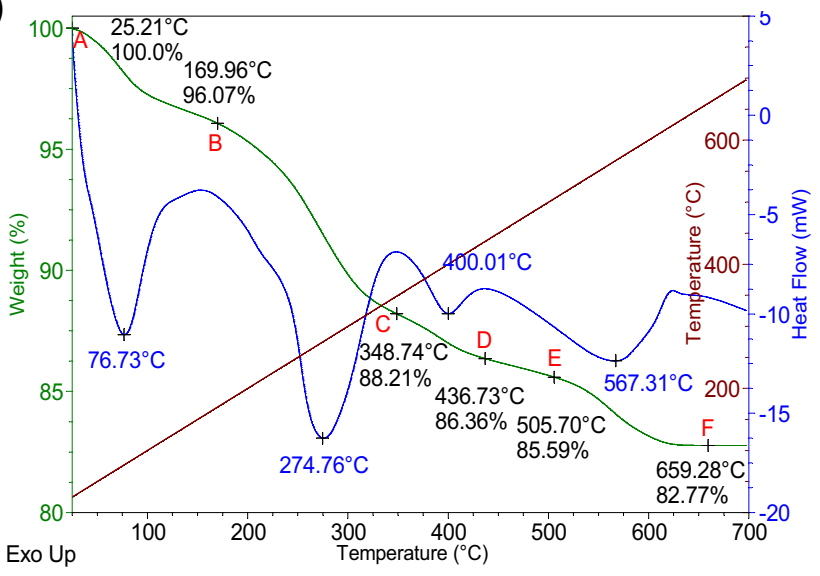

(d)

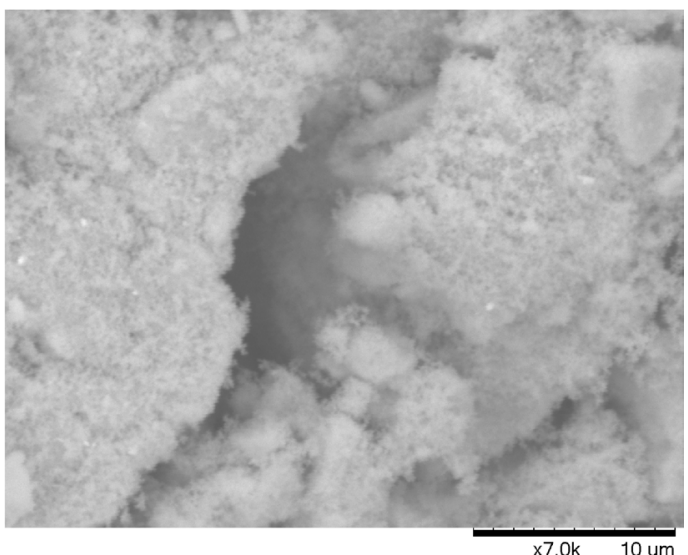

Figure 3. (a) ${ }^{1} \mathrm{H}$ MAS NMR deconvoluted spectrum, where three contributions can be identified: two corresponding to the $\mathrm{H} 1$ and $\mathrm{H} 2$ atoms at $8.70 \mathrm{ppm}$ and $8.46 \mathrm{ppm}$, respectively, and a third, parasitic signal at $1 \mathrm{ppm}$ coming from the rotor cap. The first two present higher chemical shifts than water molecules $(5 \mathrm{ppm})$, accounting for the acidity of the protons of the sample. (b) TGA/DSC curves of the thermal analysis of the AA. Labels correspond to the stoichiometric formulae $(\mathrm{A})\left(\mathrm{H}_{3} \mathrm{O}\right)_{1.20} \mathrm{H}_{0.77} \mathrm{Sb}_{2} \mathrm{O}_{6} \cdot 0.703 \mathrm{H}_{2} \mathrm{O}$ or $\mathrm{Sb}_{2} \mathrm{O}_{5} \cdot 2.89 \mathrm{H}_{2} \mathrm{O}$, (B) $\left(\mathrm{H}_{3} \mathrm{O}\right)_{1.20} \mathrm{H}_{0.77} \mathrm{Sb}_{2} \mathrm{O}_{6}$ or $\mathrm{Sb}_{2} \mathrm{O}_{5} \cdot 2.19 \mathrm{H}_{2} \mathrm{O}$, (C) $\mathrm{H}_{1.1} \mathrm{Sb}_{2} \mathrm{O}_{5.55}$ or $\mathrm{Sb}_{2} \mathrm{O}_{5} \cdot 0.55 \mathrm{H}_{2} \mathrm{O}$, (D) $\mathrm{H}_{0.32} \mathrm{Sb}_{2} \mathrm{O}_{5.16}$ or $\mathrm{Sb}_{2} \mathrm{O}_{5} \cdot 0.16 \mathrm{H}_{2} \mathrm{O}$, (E) $\mathrm{Sb}_{2} \mathrm{O}_{5}$, and $(\mathrm{F}) \mathrm{Sb}_{6} \mathrm{O}_{13}$. These structures were inferred from the total weight loss of the AA sample, and later confirmed by carefully matching up these curves with the TGA and DTA curves of the Kovalenko et al. thermolysis analysis reported for a hydrated antimony pentoxide sample ${ }^{38}$. (c,d) low magnification SEM images of the AA sample obtained by soft-chemistry oxidative hydrolysis reaction.

\begin{tabular}{|l|l|l|l|l|l|l|l|l|l|}
\hline Signal & Signal source & Line model & Amplitude & $\begin{array}{l}\text { Position } \\
(\mathbf{p p m})\end{array}$ & Width $(\mathbf{p p m})$ & Integral (\%) & $\boldsymbol{x} \boldsymbol{G} /(\mathbf{1}-\boldsymbol{x}) \boldsymbol{L}$ & $\mathbf{d C S}(\mathbf{p p m})$ & $\boldsymbol{\eta}$ \\
\hline$\# 1$ & H1 & CSA MAS & 12.62 & 8.70 & 2.65 & 81.30 & 0.00 & 10.00 & 0.50 \\
\hline$\# 2$ & H2 & CSA MAS & 1.35 & 8.46 & $2.8(1)$ & 17.49 & 0.70 & 15.00 & 0.50 \\
\hline$\# 3$ & Rotor cap & Gaus/Lor & 0.30 & 1.00 & $6.0(1)$ & 1.21 & 0.00 & - & - \\
\hline
\end{tabular}

Table 3. ${ }^{1} \mathrm{H}$ MAS NMR chemical shift anisotropy data from spectra recorded at $10 \mathrm{kHz}$. In spectra analysis, position, linewidth, and integrated area of central components were deduced with non-linear iterative techniques. The analysis of spinning sideband patterns enables a determination of the isotropic chemical shift ( $\delta$ iso), and the axiality (dCS) and asymmetry parameter $(\eta)$ of the chemical shift anisotropy tensor.

In the AA series, moisture is frequently present, and the total water amount they contain seems to vary from zero to six $\mathrm{H}_{2} \mathrm{O}$ molecules per formula unit ${ }^{1,5,17,28}$, some of which are expected to be adsorbed on the solid surface linked by $\mathrm{H}$ bonds to the outmost framework oxygen atoms and exposed acid groups. In order to assess this moisture content and to confirm the crystalline water determined by MAS NMR, a TGA/DSC analysis was performed on both, a dry, and a long-term air-stored sample. The weight and heat flow curves are summarized in Fig. 3b.

The dry sample was used to determine the quantity of hydronium and $\mathrm{H} 2$ species, obtaining values in close agreement with those derived from NMR and in agreement with the proposed structural model. It comes to no 

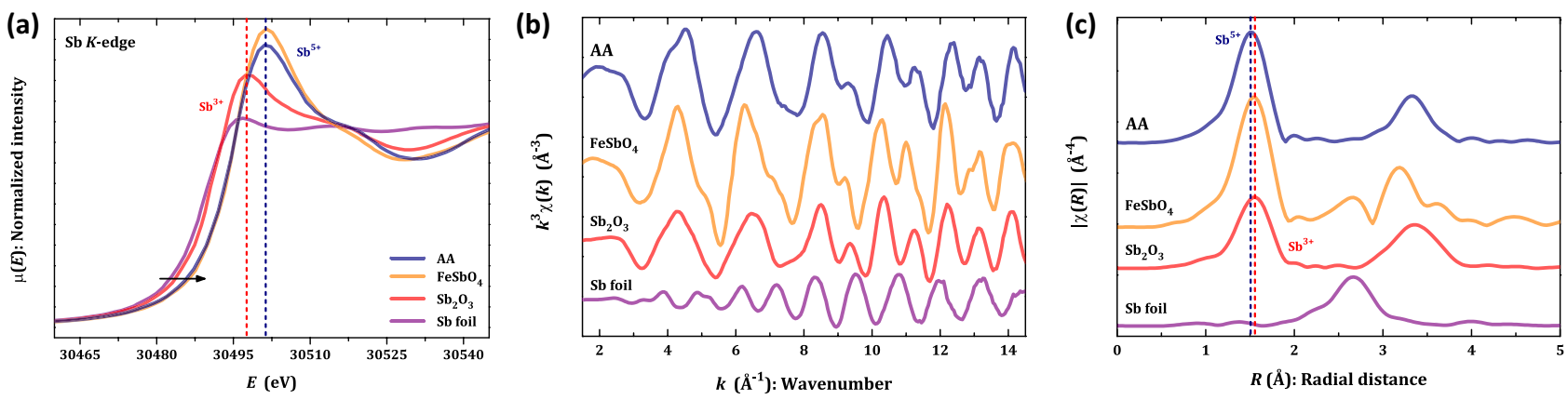

(d)

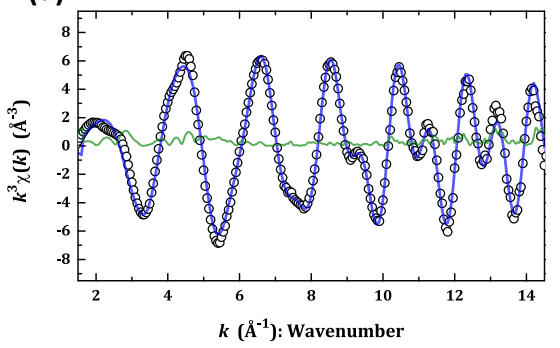

(e)

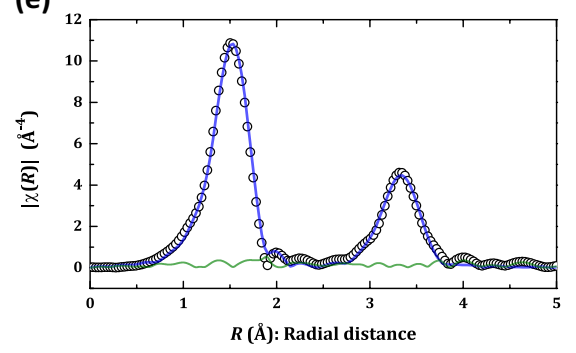

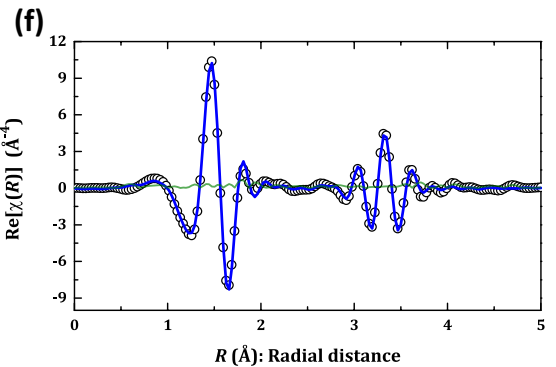

Figure 4. Structural short-range order studies. Room condition $\mathrm{Sb} K$-edge XANES spectra of AA as compared with reference samples of $\mathrm{Sb}$ foil, $\mathrm{Sb}_{2} \mathrm{O}_{3}$, and $\mathrm{FeSbO}_{4}(\mathbf{a})$. The $k^{3}$-weighted EXAFS signals (b) and their corresponding moduli of the Fourier transform $(c)$. The fitting was performed using the scattering paths in Table 4: the EXAFS oscillations $k^{3} \chi(k)(\mathbf{d})$, moduli of the Fourier transform $|\chi(R)|(\mathbf{e})$, and its real part $\operatorname{Re}[\chi(R)]$ (f) in $R$ space. The open symbol stands for the experimental point, the solid blue line is the best fit, and the green line the residue.

surprise that AA presents some major water affinity, as a small amount of moisture was adsorbed on the dry sample during the TGA/DSC experiment setup, and later degassed in the heating process up to $150{ }^{\circ} \mathrm{C}$. Seamlessly, this extraordinary water affinity was recently identified and reported by our group for a potassium pyrochlorelike niobate and tungstate ${ }^{33}$, probably bound to many series of pyrochlore-like materials as a common behaviour pattern. For the assessment of $\mathrm{H}$ content in the dry sample, this last moisture-related contribution was deducted. The final stoichiometric formula achieved with TGA/DSC for dry AA is $\left(\mathrm{H}_{3} \mathrm{O}\right)_{1.24} \mathrm{H}_{0.76} \mathrm{Sb}_{2} \mathrm{O}_{6}$, in agreement within the standard deviations with that obtained from the structural refinement. Moreover, the dehydrated sample corresponds to a stoichiometric formula close to $\mathrm{Sb}_{2} \mathrm{O}_{5} \cdot 2.19 \mathrm{H}_{2} \mathrm{O}$, which is fairly similar to the one reported by Ozawa et al. $\left(\mathrm{Sb}_{2} \mathrm{O}_{5} \cdot 2 \mathrm{H}_{2} \mathrm{O}\right)^{3}$, pioneers in the soft-chemistry procedure utilized here to synthesize the AA phase. By combining the refined crystallographic formula with the TGA results, 0.703 moisture water molecules were determined for the moisturized and long-term stored AA sample, which can be described as $\mathrm{Sb}_{2} \mathrm{O}_{5} \cdot 2.88 \mathrm{H}_{2} \mathrm{O}$. Moisture water molecules are presumed to be physisorbed on the surface of the AA crystals through hydrogen bond linkages ${ }^{1,3,36}$. The thermal decomposition steps that AA experiences upon warming up have been widely studied along the years ${ }^{6,7,37}$. Perhaps the most significant contribution in this regard is the one made by Kovalenko et al. in 2018 by studying the thermal decomposition of hydrated antimony pentoxide, obtained by oxidation of antimony(III) chloride in nitric acid and later hydrolysis in water. Authors' assessment was performed by thermal analysis in combination with mass spectrometry analysis of released gases, and reliable intermediate steps were presented. Our TGA/DSC study is in close agreement with the reported decomposition steps, and similar intermediate formulas were labelled for each meaningful step in its corresponding figure.

Scanning electron microscope. SEM images shed light on the microscopic uniformity of the of AA. This landscape is compatible with the soft-chemistry procedure here used to synthesize the solid. Figure $3 \mathrm{c}$, d shows two pictures of the long-term stored sample, displaying particles of a size smaller than a micron. This is in line with the colloidal nature of the sample, and the impossibility of collecting it from the slurry by a simple filtration process.

Structural short-range order studies. XAS is a powerful tool to probe both chemical features of the constituting elements, such as valence and coordination environment around the target atoms, and local structural information, which includes average nearest-neighbour distances and coordination number ${ }^{39}$. XANES (X-ray absorption near-edge structure) part of the XAS spectra provides information on the valence state as the edge position, such that the binding energy of the bound electrons increases with the valence ${ }^{40}$. Figure $4 \mathrm{a}$ compares the XANES at $\mathrm{Sb} K$-edge $(30.491 \mathrm{keV})$ of AA with the reference samples, including the $\mathrm{Sb}$ foil $\left(\mathrm{Sb}^{0}\right), \mathrm{Sb}_{2} \mathrm{O}_{3}$ $\left(\mathrm{Sb}^{3+}\right)$ and $\mathrm{FeSbO}_{4}\left(\mathrm{Sb}^{5+}\right)$. One may see the blue shift of the edge position when the valence state increases from 0 up to $5+$, as indicated by the black arrow. The shift $\Delta E$ of the edge energy, from the $\mathrm{Sb}^{0}$, is $1.7 \mathrm{eV}$ for valence $\mathrm{Sb}^{3+}$, while for valence $\mathrm{Sb}^{5+}$ of AA is $5.6 \mathrm{eV}$. Such a result agrees with the edge shift observed for FeSbO ${ }_{4}$ oxide, which also contains $\mathrm{Sb}^{5+}$. It is also worth noting that the XANES features of AA increase as compared to that one of $\mathrm{Sb}_{2} \mathrm{O}_{3}$, meaning that the coordination number of the first shell $\mathrm{Sb}-\mathrm{O}$ has also risen. 


\begin{tabular}{|l|l|l|l|l|}
\hline Sample & Shell & $R_{\Gamma}, \AA$ & $N_{\Gamma}$ & $\mathbf{1 0}^{-3} \times \sigma_{\Gamma}^{2}, \AA^{2}$ \\
\hline Antimonic acid & $\mathrm{Sb}-\mathrm{O}$ & $1.955(1)$ & $6.5(1)$ & $3.4(6)$ \\
\hline Edge position, $\mathrm{eV}$ & $\mathrm{Sb}-\mathrm{Sb}$ & $3.612(1)$ & $2.8(1)$ & $2.7(8)$ \\
\hline $30,495.6$ & $\mathrm{Sb}-\mathrm{O}$ & $3.898(1)$ & $6.0(1)$ & $12(1)$ \\
\hline $\boldsymbol{N}_{\text {idp }}$ & $\boldsymbol{N}_{\text {var }}$ & R-factor & $\Delta \boldsymbol{k}$-range, $\AA^{-1}$ & $\Delta R$-range, $\AA$ \\
\hline 26 & 8 & 0.0115 & $2-14.5$ & $0.9-4.2$ \\
\hline
\end{tabular}

Table 4. Structural parameters extracted from EXAFS data. $R_{\Gamma}$ is the distance from absorber atom, $N_{\Gamma}$ is the average coordination number, $\sigma_{\Gamma}^{2}$ the Debye-Waller factor, and $R$-factor stands for the quality factor of the fitting. Maximum number of independent variables as imposed by the uncertainty principle: $N_{\text {idp }} \approx 2 \Delta k \Delta \mathrm{R} / \pi$. $N_{\text {var }}$ number of variables used during the fitting procedure.

Quantitative information on the local structure was obtained using the extended part of the XAS spectra, the so-called EXAFS (extended X-ray absorption fine structure). Indeed, EXAFS spectra were recorded up to $k=16 \AA^{-1}$, as represented in Fig. $4 \mathrm{~b}$. Here, the EXAFS oscillations $k^{3} \chi(k)$ of Sb foil, $\mathrm{Sb}_{2} \mathrm{O}_{3}, \mathrm{FeSbO}_{4}$, and AA are compared, showing similarities among the oxides. This can be better seen by plotting the moduli of the Fourier transform in $R$ space in Fig. 4c: two main peaks at 1.52 and $3.35 \AA$ (not corrected by photoelectron phase-shift). In order to evaluate the pair-bond distances and the coordination numbers, the standard EXAFS equation was used, which stands for ${ }^{39}$ :

$$
\chi(k, \Gamma)=\frac{N_{\Gamma} S_{0}^{2}}{2 k R_{\Gamma}^{2}} \cdot F_{\Gamma}\left(k, R_{\Gamma}\right) \cdot \sin \left[2 k R_{\Gamma}+\varphi_{\Gamma}(k)\right] \cdot e^{-2 \sigma_{\Gamma}^{2} k^{2}} \cdot e^{-\frac{2 R_{\Gamma}}{\lambda(k)}}
$$

such that $R_{\Gamma}, N_{\Gamma}$, and $\sigma_{\Gamma}$ are the structural parameters to be determined for each photoelectron path: distance from absorber atom to its neighboring ones, coordination number of the shell, and Debye-Waller (DW) factor (it measures the mean square relative displacement), respectively. $S_{0}$ stands for the amplitude reduction factor from a previous calibration using a metallic antimony ( $S_{0}$ is equal to 0.7802 for all the samples). $F_{\Gamma}\left(k, R_{\Gamma}\right), \lambda(k)$, and $\varphi_{\Gamma}(k)$ denote the backscattered amplitude, photoelectron mean free path, and phase shift, correspondingly, which are determined by the FEFF- 8 code ${ }^{41}$.

The EXAFS signal at room temperature of AA was fitted using three neighbouring shells: one short $\mathrm{Sb}-\mathrm{O}$, one $\mathrm{Sb}-\mathrm{Sb}$, and a long $\mathrm{Sb}-\mathrm{O}$ one. All the adjusted parameters of interest in Eq. (1) are listed in Table 4. Figure 4d-f shows the quality of fitting by exhibiting the EXAFS oscillations, moduli of the Fourier transform and its real part in $R$ space, respectively. The first peak in $|\chi(R)|$ at $1.52 \AA$ (not phase-shift corrected) denotes the $\mathrm{Sb}^{5+}-\mathrm{O}$ bond with $R_{\mathrm{Sb}-\mathrm{O}}=1.955(1) \AA$ and coordination number $N_{\mathrm{Sb}-\mathrm{O}}$ around 6.5(1). Such a shell fully agrees with the pair bond $\mathrm{Sb}-\mathrm{O} 1(\times 6)$ with a distance of $1.9663(12) \AA$, as obtained from NPD. The second feature in $|\chi(R)|$ at $3.35 \AA$ has two components: a metallic-metallic pair with $R_{\mathrm{Sb}-\mathrm{Sb}}=3.612(1) \AA$ and a metallic-anion one with $R_{\mathrm{Sb}-\mathrm{O}}=3.898(1) \AA$. The $\mathrm{Sb}-\mathrm{Sb}$ pair possesses a coordination environment close to 3 , which may be associated with the non-bonding pair Sb-Sb (×6) with a metal-metal distance of 3.66307(2) $\AA$ in Table 2. The second nonbonding pair $\mathrm{Sb}-\mathrm{O}$ has $R_{\mathrm{Sb}-\mathrm{O}}=3.898(1) \AA$ and coordination number $N_{\mathrm{Sb}-\mathrm{O}}$ around 6.0(1), being similar to that obtained for Sb-O2 $(\times 12)$ with a distance of 3.845(7) $\AA$. Details on the EXAFS analyses in $\mathrm{Sb}_{2} \mathrm{O}_{3}$ and $\mathrm{FeSbO}_{4}$ samples can be found elsewhere ${ }^{19}$.

Differently from NPD, here it is not possible to identify pair containing this hydrogen by EXAFS, since the atomic number of Hydrogen is 1 ; therefore, the shortest and longest distances are missing in this study. The DW factors of the shells Sb-O (1.955(1) $\mathrm{A})$ and Sb-Sb (3.612(1) $\AA$ ) were derived as 3.4(6) and 2.7(8) $\times 10^{-3} \AA^{2}$, respectively. These values agree well with those reported for cubic $\mathrm{Sb}_{2} \mathrm{O}_{5}$, meaning that AA and the last oxide have a very similar short-range structure ${ }^{42}$, i.e. with a similar covalent framework composed by $\mathrm{Sb}^{5+}-\mathrm{O}$ pair bonds.

\section{Conclusions}

A compelling study of the so-called 'antimonic acid' structure by robust local- and long-range techniques, together with a BVEL analysis, shed light on the stoichiometry and atomic distribution in the crystal structure, and provide a plausible ionic diffusion mechanism for its well-established high proton conductivity. The structure can be defined as a defect pyrochlore, belonging to the $F d \overline{3} m$ space group. Aided by a combined Rietveld refinement from SXRD and NPD data, and by TGA/DSC and MAS NMR studies, we were capable of identifying two main types of protons in this material, one at $96 \mathrm{~g}$ Wyckoff sites that belongs to the highly delocalized hydronium subunits and presents lengthened prolate displacement ellipsoids, and another one at $48 \mathrm{f}$ positions, directly bonded at 1.12(4) $\AA$ to the oxygen atoms constituting the $B_{2} \mathrm{O}_{6}{ }^{-2}$ covalent framework within which the hydronium groups percolate. The refined crystallographic formula is $\left(\mathrm{H}_{3} \mathrm{O}\right)_{1.20(7)} \mathrm{H}_{0.77(9)} \mathrm{Sb}_{2} \mathrm{O}_{6}$, with 0.703 water molecules from physisorbed moisture per formula unit. We found neither additional $\mathrm{H}$ species nor the presence of $\mathrm{Sb}^{3+}$ remaining from the oxide precursor or generated by reduction of $\mathrm{Sb}^{5+}$ at $A$ sites. Although no additional crystallization water was found, a plausible mechanism where two $\mathrm{H}_{3} \mathrm{O}^{+}$groups within the same cavity are prone to become two $\mathrm{H}_{2} \mathrm{O}$ molecules and two $\mathrm{H} 2$ protons is proposed, endorsed by the repulsion among hydronium units sharing the same cavity, and by the $48 f$ site availability. Good Rietveld refinement reliability factors were achieved, and the XAS, the MAS NMR, and TGA/DSC results are all consistent with the proposed model. In particular, XANES endorsed the pentavalent state of antimony ion in AA, while EXAFS probed the covalent framework composed by $\mathrm{Sb}^{5+}$ and $\mathrm{O} 1$ atoms. 


\section{Methods}

Sample preparation. All the commercially available ReagentPlus or Analytical-grade reagents were purchased at Sigma Aldrich and Fisher Scientific.

Antimonic acid was obtained by an oxidative hydrolysis soft-chemistry reaction. It begins from $\mathrm{Sb}_{2} \mathrm{O}_{3}$ and a $31 \% \mathrm{H}_{2} \mathrm{O}_{2}$ solution, following previously described procedures ${ }^{3,43}$. The mixture was stirred at $343 \mathrm{~K}$ for $24 \mathrm{~h}$, while the hereunder reaction occurs:

$$
\mathrm{Sb}_{2} \mathrm{O}_{3}+2 \mathrm{H}_{2} \mathrm{O}_{2}+(p-1) \mathrm{H}_{2} \mathrm{O} \rightarrow\left(\mathrm{H}_{3} \mathrm{O}\right)_{p} \mathrm{H}_{2-p} \mathrm{Sb}_{2} \mathrm{O}_{6} .
$$

The white colloidal slurry is centrifuged at $15,000 \mathrm{rpm}$ for $10 \mathrm{~min}$ until nearly complete sedimentation. The product, a glassy-white solid, is then dried in air at $105-107^{\circ} \mathrm{C}$ for $48 \mathrm{~h}$ and finally ground.

The $\left(\mathrm{H}_{3} \mathrm{O}\right)_{p} \mathrm{H}_{2-p} \mathrm{Sb}_{2} \mathrm{O}_{6}$ sample was firstly investigated utilizing X-ray powder diffraction (XRD). Laboratory XRD data were collected with a conventional diffractometer $(40 \mathrm{kV}, 30 \mathrm{~mA})$ in Bragg-Brentano reflection geometry with $\mathrm{Cu} \mathrm{K} \mathrm{K}_{\alpha}$ radiation $\left(\lambda_{\text {mean }}=1.5418 \AA\right.$ ). The SXRD pattern was collected at the CELLS $-A L B A$ facility, Barcelona (Spain), in the MSPD high-angular resolution diffractometer under an incident beam with an energy of $28 \mathrm{keV}$ and a wavelength of $\lambda=0.44271 \AA$. For determining the instrumental broadening, the sample was characterized together with a powdered $\mathrm{Na}_{2} \mathrm{Ca}_{3} \mathrm{Al}_{2} \mathrm{~F}_{14}$ fluoride (NAC) standard. The high-angular resolution mode (MAD set-up) was used on the MSPD-diffractometer ${ }^{44}$. The polycrystalline powder was contained in a spinning glass capillary of $0.7 \mathrm{~mm}$ diameter. For the NPD experiments, the D2B high-resolution two-axis diffractometer was used, installed at the Institut Laue-Langevin, in Grenoble (France). The sample (about 2-3 g) was contained in a vanadium can. The full diffraction patterns were collected in a $2 \mathrm{~h}$-long analysis time. A wavelength of $1.5947 \AA$ was selected from a Ge monochromator; the measurement temperature was $298 \mathrm{~K}$.

Structural refinement from synchrotron X-ray and neutron diffraction data. FULLPROF ${ }^{45}$ software (see "Methods") was used for performing the combined Rietveld refinement ${ }^{46}$ from SXRD and NPD data. A relative pattern weight of 0.10/0.90 favouring NPD data was considered, as it presents an absence of form factor and exceptional sensitivity for both hydrogen and oxygen atoms, essential for determining their positions, occupancies and atomic displacement factors (ADPs). Moreover, $\mathrm{H}^{+}$atoms are invisible to $\mathrm{X}$-rays and the atomic weight ratio between $\mathrm{Sb}$ and $\mathrm{O}$ is large enough for the SXRD to differentiate them even at low pattern weighting. The best ADPs and lowest Rietveld reliability factors were obtained for the announced relationship.

The Thompson-Cox-Hastings ${ }^{47}$ pseudo-Voigt convoluted with axial divergence asymmetry over SXRD data were used to determine the crystallite size. A calculated $\mu R=0.92$ absorption correction coefficient determined by adopting a 0.5 packed factor was included in the refinement for compensating transmission and absorption of the X-rays through the irradiated cylindrical volume of the sample. An apparent isotropic crystallite size of $42.00(8) \mathrm{nm}$ and average maximum generalized strain of $\varepsilon=6.666(7) \times 10^{-4}$ were obtained through microstrainand domain size-determining FULLPROF modules. For the NPD data treatment, a pseudo-Voigt ${ }^{48}$ function with the asymmetry correction published by Berar and Baldinozzi ${ }^{49}$ were respectively employed for the simulation of the peak shape and the asymmetry assessment.

Both SXRD and NPD backgrounds were linearly interpolated between 68 and 44 individual refined points. The coherent neutron scattering lengths used in the Rietveld refinement are internally tabulated in the program FULLPROF, rated in 5.570, 5.803, and $-3.739 \mathrm{fm}$ for $\mathrm{Sb}, \mathrm{O}$, and $\mathrm{H}$ atoms, respectively.

BVEL was carried out with BondStr ${ }^{50}$ software (see "Methods"), a module embedded in the FULLPROF toolbar. For ensuring a percolation energy convergence of a few hundredths of electron volt, BVEL analysis considering $\mathrm{H}^{+}$as the mobile ion was computed by applying a grid resolution of $0.1 \AA$ and a percolation radius of $8 \AA$, suiting with the optimal parameters described by Katcho et al. in their high-throughput BVEL calculation of $\mathrm{Li}$ and $\mathrm{Na}$ ionic conductors ${ }^{50}$. As both mobile ion share almost the same minimum site-energy $(-2.93$ and $-3.05 \mathrm{eV}$ for $\mathrm{H} 1$ and $\mathrm{H} 2$, respectively), and that they fit in the same conduction path, we tacitly assume that the migration energy $E_{m}$ is equivalent to the threshold energy $E_{t h}$ here determined, defined as the energy at which the proton pathway starts percolating across the unit cell ${ }^{50}$. Hence, undertaking a multiple-technique approach, we disclose a detailed and comprehensible structural description of the AA, which is compatible with its main chemical properties.

Magic-angle spinning nuclear magnetic resonance spectroscopy. The chemical shift anisotropy is the interaction between the external magnetic field $\mathrm{B}_{0}$ and the electron density surrounding the nucleus, owing to the magnetic moment coming from its rather ellipsoidal shape. The weak secondary magnetic fields that are generated are added or subtracted to $\mathrm{B}_{0}$, modifying the magnetic field around the nucleus, and therefore its resonance frequency in a so-called 'shielding' process that results in a chemical shift. The three main values of the shielding associated tensor are frequently expressed as a function of the isotropic chemical shift ( $\delta$ iso), and the axiality (dCS) and asymmetry parameter $(\eta)$ of the chemical shift anisotropy tensor. For nucleus in an axial symmetry site, it is true that $\delta x x=\delta y y \neq \delta z z$ and $\eta=0$. The shape of the powder sample line is very different, depending on the symmetry of both the shielding tensor and the site where the nucleus is located. The MAS experiment ('magic angle spinning' or rotation of the sample around the magic angle) can average the chemical shift anisotropy. Even slow spinning provides very narrow lines, although there may be a substantial number of spinning sidebands. It is interesting to note that the orientation-dependent information of the interaction remains, embedded in the amplitudes of the spinning sidebands. Indeed, a simulation can extract the principal values of the chemical shift anisotropy from slow speed MAS spectra.

${ }^{1}$ H MAS NMR spectrum was recorded on a Bruker AVANCE 400 spectrometer. Single pulse sequences were used to irradiate the sample at the ${ }^{1} \mathrm{H}$ resonance frequency in a $9.4 \mathrm{~T}(400 \mathrm{MHz})$ magnetic field. The sample was 
placed on zirconia rotors that rotate inside the probe at an angular frequency of $10 \mathrm{kHz}$ around the magic angle ( $54^{\circ} 44^{\prime}$ with respect to the external magnetic field). NMR spectrum was obtained after excitation of the sample with a $\pi / 2$ pulse duration of $4.7 \mu$ s and an interval between successive accumulations of $5 \mathrm{~s}$. The total number of accumulations was 72 . To determine the values of the chemical shift, tetramethylsilane was used as internal standard. By adding the components as a combined Lorentzian-Gaussian form, a calculated envelope that reproduces the spectrum is obtained, from which the intensity, position (chemical shift) and width parameters of central components were deduced with non-linear iterative techniques (DMFIT software ${ }^{51}$, see "Methods"). The analysis of spinning sideband patterns enables a determination of chemical shift, dCS and $\eta$ parameters.

X-ray absorption spectroscopy at the CLAESS beamline of the ALBA synchrotron. The X-ray absorption process was performed by measuring the photon flux through three ionization chambers. This wellestablished technique used in transmission mode provided an exact measurement of the X-ray absorption coefficient. The resulting absorption spectra were then characterized by one or more jumps (absorption edges), whose energy positions are element specific since they coincide with the energy of the corresponding atomic core level. The X-ray transitions are controlled by the dipolar selection rules relating to well-defined atomic symmetry of the involved core hole and the final state angular momenta. XANES spectra show a remarkable site-specific behaviour, because they are sensibly affected by the strong spatial localization of the initial core-shell state.

Short-range atomic studies were performed by means of XAS at the BL22-CLÆSS beamline of the Spanish synchrotron, CELLS-ALBA, Barcelona, with electron energy and current in the ring of $3 \mathrm{GeV}$ and $200 \mathrm{~mA}$, respectively. Data acquisition was performed with a double crystal monochromator with two $\mathrm{Si}(311)$ crystal pairs and three ionization chambers for determining the photon flux before/after the sample and before/after the metal foil employed for energy calibration. In this way, the X-ray absorption coefficient may be exactly measured. Details on the beamline setup can be found elsewhere ${ }^{52}$. Concerning the sample preparation for XAS measurements, the samples were ground in an agate mortar with an inert matrix (boron-nitride, BN), pelletized into disks to optimize the absorption jump of the XANES spectrum, and then protected with Kapton tape. The reference samples such as $\mathrm{Sb}$ foil (>95\%) and $\mathrm{Sb}_{2} \mathrm{O}_{3}(99.7 \%)$ were purchased from Aldrich and Alfa Aesar, respectively. $\mathrm{FeSbO}_{4}$ was synthesized using solid-state reaction method, as detailed elsewhere ${ }^{19}$.

Complementary techniques. The TGA/DSC characterization was performed in a Mettler TA3000 system equipped with a DSC Q-100 unit. The measurements were performed in heating runs from room temperature to $700{ }^{\circ} \mathrm{C}$ with a rate of $10 \mathrm{~K} \mathrm{~min}^{-1}$ for powder samples encapsulated in standard alumina crucibles. About 49 and $56 \mathrm{mg}$ of sample were used for the dry-basis and long-term stored AA experiments, correspondingly. The thermal decomposition reaction of the AA is determined as follows:

$$
3\left(\mathrm{H}_{3} \mathrm{O}\right)_{p} \mathrm{H}_{2-p} \mathrm{Sb}_{2} \mathrm{O}_{6} \cdot n \mathrm{H}_{2} \mathrm{O} \stackrel{\Delta}{\longrightarrow} \mathrm{Sb}_{6} \mathrm{O}_{13}+\mathrm{O}_{2}+(3+3 p+n) \mathrm{H}_{2} \mathrm{O} .
$$

SEM experiments were conducted with a Hitachi TM1000 (Hitachi High-Technologies Corporation, Minato, Tokyo, Japan) desktop instrument with an acceleration voltage of $1.5 \mathrm{kV}$ and a $90 \mathrm{~s}$ acquisition time.

Details on data processing. FULLPROF $F^{45}$ toolbar software (Version 5th May 2020, Institut Laue-Langevin Grenoble, France, https://www.ill.eu/sites/fullprof/) includes the embedded modules WinPLOTR-2006 (Version 0.50 of June 2013, Institut Laue-Langevin Grenoble, France), BondSTR (Version July 2010, Institut Laue-Langevin Grenoble, France) and GFOURIER (Graphic Fourier Program, Version 04.06 of 2007, Univ. La Laguna, Tenerife, Spain), that were used for the Rietveld Refinement, the Fourier difference density maps calculation, and the BVEL analysis, respectively. Data processing was performed with OriginPro (Version 8 SR0 and 2018 SR1, OriginLab, Northampton, MA, USA, https://www.originlab.com). Crystal structure projections were generated using VESTA ${ }^{53}$ (Visualization for Electronic and STructural Analysis, Version 3.5.5 of 26th September 2020, 64-bit Edition, https://jp-minerals.org/vesta/en/) graphing tools. ATHENA and ARTEMIS from the Demeter suite $^{41}$ (Version 0.9.26, 64-bit Edition, https://bruceravel.github.io/demeter/) were employed to process the XAFS data. MAS NMR spectra were treated with the DMFIT software ${ }^{51}$ (Version 2020.03.06, https://nmr. cemhti.cnrs-orleans.fr/dmfit/).

\section{Data availability}

The datasets generated during and analysed during the current study are available from the corresponding author on reasonable request.

Received: 4 June 2021; Accepted: 17 August 2021

Published online: 07 September 2021

\section{References}

1. Abe, M. \& Ito, T. Synthetic inorganic ion-exchange materials. XII. Some observation on surface structure and cation-exchange behaviour of three different antimonic acids. Bull. Chem. Soc. Jpn. 41, 2366-2371 (1968).

2. England, W. A. \& Slade, R. C. T. NMR Study of proton transport in crystalline antimonic acid. Solid State Commun. 33, 997-999 (1980).

3. Ozawa, Y., Miura, N., Yamazoe, N. \& Seiyama, T. Proton conduction in thermally treated antimonic acid samples. Chem. Lett. https://doi.org/10.1246/cl.1982.1741 (1982).

4. Amarilla, J. M. et al. Antimonic acid and sulfonated polystyrene proton-conducting polymeric composites. Solid State Ion. 127, 133-139 (2000). 
5. Baetsle, L. H. \& Huys, D. Structure and ion-exchange characteristics of polyantimonic acid. J. Inorg. Nucl. Chem. 30, 639-649 (1968).

6. Veselý, V. \& Pekárek, V. Synthetic inorganic ion-exchangers-I. Hydrous oxides and acidic salts of multivalent metals. Talanta 19, 219-262 (1972).

7. Belinskaya, F. A. \& Militsina, E. A. Inorganic ion-exchange materials based on insoluble antimony(V) compounds. Russ. Chem. Rev. 49, 933-952 (1980).

8. Abe, M., Tsuji, M. \& Kimura, M. Synthetic inorganic ion-exchange materials. XXXI. Ion-exchange behavior of tervalent metals and rare earth elements on crystalline antimonic(V) acid cation exchanger. Bull. Chem. Soc. Jpn. 54, 130-134 (1981).

9. Dyer, A. Ion exchange. In Reference Module in Chemistry, Molecular Sciences and Chemical Engineering (Elsevier, 2013). https:// doi.org/10.1016/B978-0-12-409547-2.04402-4..

10. Wang, B. et al. Mn-substituted tunnel-type polyantimonic acid confined in a multidimensional integrated architecture enabling superfast-charging lithium-ion battery anodes. Adv. Sci. 8, 2002866 (2021).

11. Li, G., Yang, N., Yang, X., Wang, W. \& Zhang, W. F. Reagent dependency of the extent of organic compound degradation ability under visible light irradiation. J. Phys. Chem. C 115, 13734-13738 (2011).

12. Chen, J. et al. Antimony oxide hydrate $\left(\mathrm{Sb}_{2} \mathrm{O}_{5} \cdot 3 \mathrm{H}_{2} \mathrm{O}\right)$ as a simple and high efficient photocatalyst for oxidation of benzene. Appl. Catal. B Environ. 210, 379-385 (2017).

13. England, W., Cross, M., Hamnett, A., Wiseman, P. \& Goodenough, J. Fast proton conduction in inorganic ion-exchange compounds. Solid State Ion. 1, 231-249 (1980).

14. Slade, $\mathrm{R}$. Ac and dc conductivity of crystalline pyrochlore antimonic acid, $\mathrm{Sb}_{2} \mathrm{O}_{5} \cdot \mathrm{nH}_{2} \mathrm{O}$. Solid State Ion. 35, 29-33 (1989).

15. Möller, T. et al. Titanium antimonates in various Ti:Sb ratios: Ion exchange properties for radionuclide ions. J. Mater. Chem. 13, 535-541 (2003).

16. Sivaiah, M. V., Venkatesan, K. A., Krishna, R. M., Sasidhar, P. \& Murthy, G. S. Ion exchange properties of strontium on in situ precipitated polyantimonic acid in amberlite XAD-7. Sep. Purif. Technol. 44, 1-9 (2005).

17. Mellor, J. W. A Comprehensive Treatise on Inorganic and Theoretical Chemistry Vol. IX (Green and Co., 1929).

18. Shi, J. et al. A novel Sn2Sb $2 \mathrm{O} 7$ nanophotocatalyst for visible-light-driven $\mathrm{H} 2$ evolution. Nano Res. 5, 576-583 (2012).

19. Mayer, S. F. et al. A comprehensive examination of the local- and long-range structure of Sb6O13 pyrochlore oxide. Sci. Rep. 10, $16956(2020)$.

20. Berzelius, J. J. II. Die Oxyde des Antimons. Schweigger's J. Chem. Phys. 6, 144 (1812).

21. Rose, H. III. Ueber die verbindungen des Antimons mit Chlor und Schwefel. Poggendorff's Ann. Phys. Chem. 3, 441 (1824).

22. Heffter, L. On the salts of antimonic acid. The London, Edinburgh Dublin Philos. Mag. J. Sci. 4, 398-399 (1852).

23. Pauling, L. The formulas of antimonic acid and the antimonates. J. Am. Chem. Soc. 55, 1895-1900 (1933).

24. Siebert, H. Ultrarotspektren von Tellursäuren, Telluraten und Antimonaten. ZAAC J. Inorg. Gen. Chem. 301, 161-170 (1959).

25. Baes, C. F. \& Mesmer, R. E. The Hydrolysis of Cations (Wiley, 1976).

26. Filella, M., Belzile, N. \& Chen, Y. W. Antimony in the environment: A review focused on natural waters II. Relevant solution chemistry. Earth Sci. Rev. 59, 265-285 (2002).

27. Accornero, M., Marini, L. \& Lelli, M. The dissociation constant of antimonic acid at 10-40 ${ }^{\circ}$ C. J. Solut. Chem. 37, 785-800 (2008).

28. Abe, M. \& Ito, T. Synthetic inorganic ion-exchange materials. X. Preparation and properties of so-called antimonic (V) acid. Bull. Chem. Soc. Jpn. 41, 333-342 (1968).

29. Dehlinger, U. \& Glocker, R. Über den atomaren Aufbau der Antimonoxyde. Zeitschrift für Anorg. und Allg. Chemie 165, 41-45 (1927).

30. Slade, R. C. T., Hall, G. P., Ramanan, A. \& Prince, E. Structure and proton conduction in pyrochlore-type antimonic acid: A neutron diffraction study. Solid State Ion. 92, 171-181 (1996).

31. Mayer, S. F., Falcón, H., Fernandez-Diaz, M. T., Campos-Martin, J. \& Alonso, J. A. Structure-properties relationship in the hydronium-containing pyrochlores $(\mathrm{H} 3 \mathrm{O}) 1+\mathrm{pSb} 1+\mathrm{pTe} 1-\mathrm{pO} 6$ with catalytic activity in the fructose dehydration reaction. Dalt. Trans. 49, 11657-11667 (2020).

32. Vaivars, G., Kleperis, J., Azens, A., Granqvist, C. \& Lusis, A. Proton conducting composite electrolytes based on antimonic acid. Solid State Ion. https://doi.org/10.1016/s0167-2738(97)00049-0 (1997).

33. Mayer, S. F., Falcón, H., Fernández-Díaz, M. T. \& Alonso, J. A. The crystal structure of defect KBB’O6 pyrochlores (B, B': Nb, W, $\mathrm{Sb}, \mathrm{Te}$ ) revisited from neutron diffraction data. Curr. Comput.-Aided Drug Des. 8, 1-11 (2018).

34. Scherrer, P. Bestimmung der Größe und der inneren Struktur von Kolloidteilchen mittels Röntgenstrahlen. In Kolloidchemie Ein Lehrbuch. Chemische Technologie in Einzeldarstellungen 387-409 (Springer, Berlin, Heidelberg, 1912). https://doi.org/10.1007/ 978-3-662-33915-2_7.

35. Langford, J. I. \& Wilson, A. J. C. Scherrer after sixty years: A survey and some new results in the determination of crystallite size. J. Appl. Crystallogr. 11, 102-113 (1978).

36. Stewart, D. J., Knop, O., Ayasse, C. \& Woodhams, F. W. D. Pyrochlores. VII. The oxides of antimony: An X-ray and Mössbauer Study. Can. J. Chem. 50, 690-700 (1972).

37. Jander, G. \& Simon, A. Zur Kenntnis der Antimonpentoxydhydrate. Zeitschrift für Anorg. und Allg. Chemie 127, 68-82 (1923).

38. Kovalenko, L. Y., Yaroshenko, F. A., Burmistrov, V. A., Isaeva, T. N. \& Galimov, D. M. Thermolysis of hydrated antimony pentoxide. Inorg. Mater. 55, 586-592 (2019).

39. Lee, P. A., Citrin, P. H., Eisenberger, P. \& Kincaid, B. M. Extended X-ray absorption fine structure its strengths and limitations as a structural tool. Rev. Mod. Phys. 53, 769-806 (1981).

40. Bunker, G. Introduction to XAFS: A Practical Guide to X-ray Absorption Fine Structure Spectroscopy. (Cambridge University Press, 2010). https://doi.org/10.1017/CBO9780511809194.

41. Ravel, B. \& Newville, M. ATHENA, ARTEMIS, HEPHAESTUS: Data analysis for X-ray absorption spectroscopy using IFEFFIT. J. Synchrotron Radiat. 12, 537-541 (2005).

42. Scheinost, A. C. et al. Quantitative antimony speciation in shooting-range soils by EXAFS spectroscopy. Geochim. Cosmochim. Acta 70, 3299-3312 (2006).

43. Jang, J. \& Seung-Joo, K. Photoelectrochemical properties of nanocrystalline Sb6O13, MgSb2O6, and ZnSb2O6-based electrodes for dye-sensitized solar cells. Jpn. J. Appl. Phys. 51, 1-4 (2012).

44. Fauth, F. et al. The crystallography stations at the Alba synchrotron. Eur. Phys. J. Plus 130, 160 (2015).

45. Rodríguez-Carvajal, J. FULLPROF: A program for rietveld refinement and pattern matching analysis. In Abstracts of Satellite Meeting on Powder Diffraction of the XV Congress of the IUCr 127 (1990).

46. Rietveld, H. M. A profile refinement method for nuclear and magnetic structures. J. Appl. Crystallogr. 2, 65-71 (1969).

47. Finger, L. W., Cox, D. E. \& Jephcoat, A. P. Correction for powder diffraction peak asymmetry due to axial divergence. J. Appl. Crystallogr. 27, 892-900 (1994).

48. Wertheim, G. K., Butler, M. A., West, K. W. \& Buchanan, D. N. E. Determination of the Gaussian and Lorentzian content of experimental line shapes. Rev. Sci. Instrum. 45, 1369-1371 (1974).

49. Berar, J. F. \& Baldinozzi, G. Modeling of line-shape asymmetry in powder diffraction. J. Appl. Crystallogr. 26, 128-129 (1993).

50. Katcho, N. A. et al. An investigation of the structural properties of Li and Na fast ion conductors using high-throughput bondvalence calculations and machine learning. J. Appl. Crystallogr. 52, 148-157 (2019).

51. Massiot, D. et al. Modelling one- and two-dimensional solid-state NMR spectra. Magn. Reson. Chem. 40, 70-76 (2002). 
52. Simonelli, L. et al. CLAESS: The hard X-ray absorption beamline of the ALBA CELLS synchrotron. Cogent Phys. 3, 1-10 (2016).

53. Momma, K. \& Izumi, F. VESTA 3 for three-dimensional visualization of crystal, volumetric and morphology data. J. Appl. Crystal$\log$. 44, 1272-1276 (2011)

\section{Acknowledgements}

We are grateful to the Spanish Ministry of Economy and Competitivity for granting the project MAT201784496-R. We thank ILL (Grenoble, France) and CELLS-ALBA (Barcelona, Spain) for making all the facilities available for the neutron and synchrotron radiation experiments. In addition, the authors want to thank Dr. Nebil Katcho for its latest update of the BondStr software, which made possible an adequate assessment of each proton site energy.

\section{Author contributions}

S.F.M., M.T.F.D., and J.A.A. carried out the growth of the samples and their general structural characterization. J.E.R., C.M., and J.G. performed the XAFS experiments. I.S. performed the NMR measurements. The data processing and analysis have been carried out by S.F.M. and J.A.A. (SXRD and NPD), I.S. (NMR), J.E.R. (XAFS), and S.F.M. (TGA/DSC). The research design and the manuscript have been written by S.F.M., M.C.A. and J.A.A. All the authors discussed the results and commented on the manuscript.

\section{Competing interests}

The authors declare no competing interests.

\section{Additional information}

Supplementary Information The online version contains supplementary material available at https://doi.org/ 10.1038/s41598-021-97147-0.

Correspondence and requests for materials should be addressed to S.F.M.

Reprints and permissions information is available at www.nature.com/reprints.

Publisher's note Springer Nature remains neutral with regard to jurisdictional claims in published maps and institutional affiliations.

(c) (i) Open Access This article is licensed under a Creative Commons Attribution 4.0 International License, which permits use, sharing, adaptation, distribution and reproduction in any medium or format, as long as you give appropriate credit to the original author(s) and the source, provide a link to the Creative Commons licence, and indicate if changes were made. The images or other third party material in this article are included in the article's Creative Commons licence, unless indicated otherwise in a credit line to the material. If material is not included in the article's Creative Commons licence and your intended use is not permitted by statutory regulation or exceeds the permitted use, you will need to obtain permission directly from the copyright holder. To view a copy of this licence, visit http://creativecommons.org/licenses/by/4.0/.

(c) The Author(s) 2021 